\title{
Active-Layer Soil Moisture Content Regional Variations in Alaska and Russia by Ground-Based and Satellite-Based Methods, 2002 through 2014
}

\author{
Reginald R. Muskett' ${ }^{1}$, Vladimir E. Romanovsky ${ }^{1,2}$, William L. Cable ${ }^{1}$, Alexander L. Kholodov ${ }^{1}$ \\ ${ }^{1}$ Geophysical Institute, University of Alaska Fairbanks, Fairbanks, USA \\ ${ }^{2}$ Tyumen State Oil and Gas University, Tyumen, Russia \\ Email: reginald.muskett@gmail.com
}

Received 20 December 2014; accepted 11 January 2015; published 19 January 2015

Copyright (C) 2015 by authors and Scientific Research Publishing Inc.

This work is licensed under the Creative Commons Attribution International License (CC BY). http://creativecommons.org/licenses/by/4.0/

(c) (i) D Den Access

\section{Abstract}

Soil moisture is a vital physical parameter of the active-layer in permafrost environments, and associated biological and geophysical processes operative at the microscopic to hemispheric spatial scales and at hourly to multi-decadal time scales. While in-situ measurements can give the highest quality of information on a site-specific basis, the vast permafrost terrains of North America and Eurasia require space-based techniques for assessments of cause and effect and long-term changes and impacts from the changes of permafrost and the active-layer. Satellitebased 6.925 and $10.65 \mathrm{GHz}$ sensor algorithmic retrievals of soil moisture by Advanced Microwave Scanning Radiometer-Earth Observation System (AMSR-E) onboard NASA-Aqua and followon AMSR2 onboard JAXA-Global Change Observation Mission-Water-1 are ongoing since July 2002. Accurate land-surface temperature and vegetation parameters are critical to the success of passive microwave algorithmic retrieval schemes. Strategically located soil moisture measurements are needed for spatial and temporal co-location evaluation and validation of the space-based algorithmic estimates. We compare on a daily basis ground-based (subsurfaceprobe) 50- and 70-MHz radio-frequency soil moisture measurements with NASA- and JAXA-algorithmic retrieval passive microwave retrievals. We find improvements in performance of the JAXA-algorithm (AMSR-E reprocessed and AMSR2 ongoing) relative to the earlier NASA-algorithm version. In the boreal forest regions, accurate land-surface temperatures and vegetation parameters are still needed for algorithmic retrieval success. Over the period of AMSR-E retrievals, we find evidence of at the high northern latitudes of growing terrestrial radio-frequency interference in the $10.65 \mathrm{GHz}$ channel soil moisture content. This is an important error source for satellite-based active and passive microwave remote sensing soil moisture retrievals in Arctic regions that must be addressed. 


\title{
Keywords
}

\author{
Soil Moisture, Active Layer, Radio, Microwave, Remote Sensing, AMSR-E, AMSR2, NASA, JAXA, \\ Alaska, Russia
}

\section{Introduction}

Soil moisture is vital for life, environment and energy-chemical cycles, runoff and evapotranspiration, erosion and weathering [1]-[6]. The distribution of soil moisture in horizontal and vertical extent shows fine-scale heterogeneity by variations of soil mineral and organic composition, hydrologic conductivity, porosity and macroporosity, structure and texture [2]. In the case of bare and sparsely vegetated ground, soil color can influence albedo thus affecting evaporative drying. Topography at large-to-small scales affects soil moisture through variations in aspect, curvature, relative elevation and slope. Vegetation characteristics such as density, structure and general type-classes also affect soil moisture at various spatial and temporal scales. Meteorology affects soil moisture through spatial and temporal variations of humidity, precipitation, solar radiation, surface temperature and surface wind [4]-[6].

The launch of Seasat and Nimbis-7 in 1978 had the first passive microwave remote sensing instrument the Scanning Multichannel Microwave Radiometer (SMMR) to extract soil moisture information based on the contrast of the dielectric constant of mineral soil and pore water on a global basis [7] [8]. Preceding these missions were theoretical and applied research by the Jet Propulsion Laboratory, California Institute of Technology that lead to the theory of passive microwave algorithmic retrieval of soil moisture and sensor design [9]. The Defense Meteorological Satellite Program Special Sensor Microwave/Imager (SSM/I) in the late-1980s and followed by the Tropical Rainfall Measuring Mission/Microwave Imager were useful in studies of soil moisture proxies without having dedicated retrieval algorithms and sensor channels [10] [11]. The first dedicated soil moisture mission by passive microwave sensor was the JAXA Advanced Microwave Scanning Radiometer (AMSR) on the Advanced Earth Observing System (ADEOS) in 1996 (10-month duration) and followed by AMSR-E on NASA-Aqua in 2002 and AMSR-J on ADEOS-II in 2002 (11-month duration) and currently by AMSR2 on the Global Climate Observing Mission-Water-1 since 2012 [12]-[14].

Our investigation focuses on comparisons of soil moisture content derived by satellite-based microwave frequency sensor algorithmic retrievals with subsurface-proberadio-frequency measurements from sites in Alaska and Russia. The comparisons are for a period from July 2002 through December 2013. The comparisons are point-wise on a same-day-month through the years. The geographic distributions of the ground measurement locations make them of interest for comparison with retrievals by space-based radio frequency sensors (Figure $1)$.

\section{Satellite-Based 6.925 and 10.65 GHz Derived Soil Moisture Content}

We use global soil moisture content from the JAXA AMSR-E and AMSR2 passive microwave sensors and retrieval algorithms. We examine retrievals most recently developed by JAXA (JAXA-algorithm for AMSR-E reprocess and AMSR2) and previously by NASA (NASA-algorithm for AMSR-E).

The design and functionality of AMSR-E deployed on NASA-Aqua satellite for the NASA Earth Observation Mission derives from the earlier designs employed in AMSR versions flown during the JAXA Advanced Earth Observation System missions I and II [13] [15]. These and current sensors have legacy with conical-mirror scanning (40 Rotations Per Minute-RPM) design concepts employed in the SMMR and SSM/I (new Figure) [15]-[17]. The NASA-Aqua satellite in polar sun-synchronous 98.2 inclination $705 \mathrm{~km}$ altitude orbit with local equator crossing times of 13:30 (ascending) and 01:30 (descending) since launch in 2002 maintained the leading position of the A-Train multi-satellite configuration up until January 2012when the lead position was assumed by GCOM-W1 carrying the AMSR2 sensor, Figure 2 [18] [19]. AMSR-E operated from June 2002 to 4 October 2011 at which time the mechanical rotating assembly experienced partial failure reducing to 4 RPM (safe mode) and then was stopped. Since December 42012 AMSR-E was restarted successfully with 2 RPM [19] [20]. From this time AMSR-E has been in an engineering-testing mode. The Slow-Rotation datasets are available from JAXA upon request [21]. 

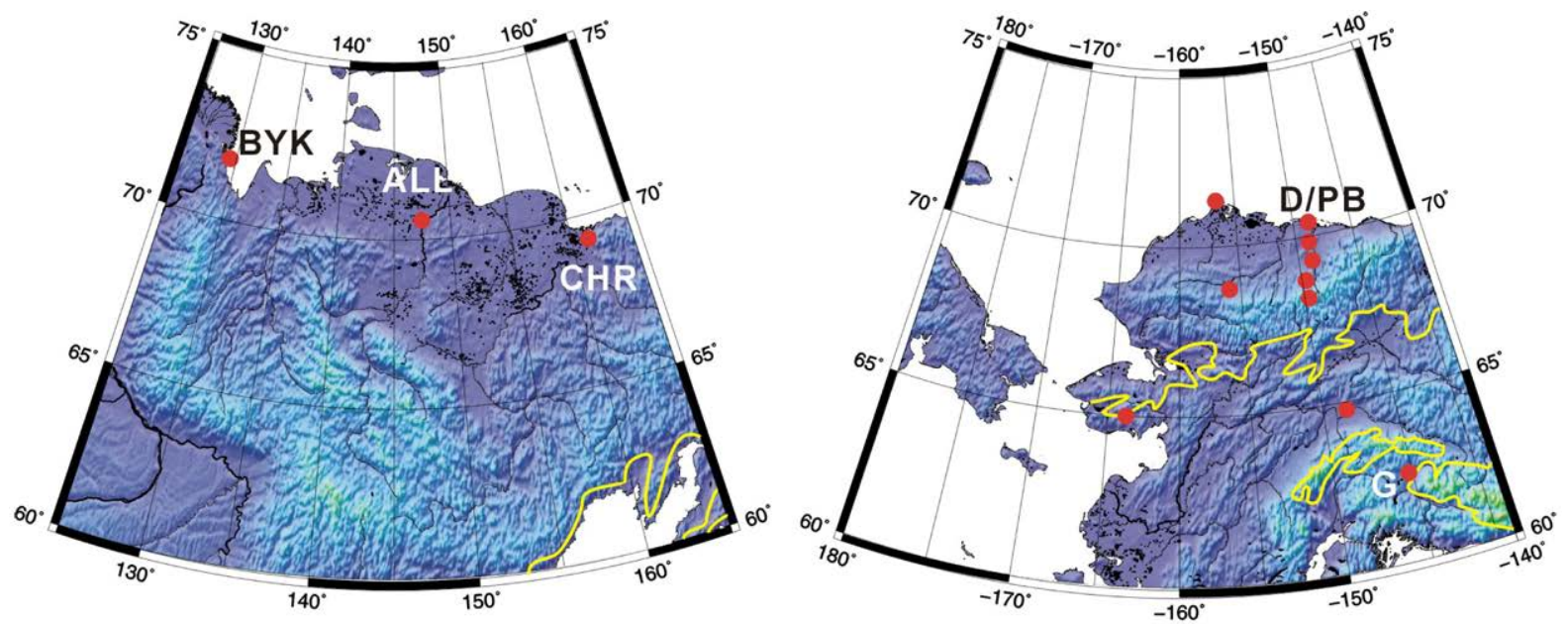

5001000150020002500300035004000450050005500

Elevation (m, EGM96/WGS84)

Figure 1. Digital elevation maps of sites of soil water content sites in Alaska and Russia marked by red dots. Locations mentioned in the text are Bykovsky (BYK), Allaiha (ALL) and Chersky (CHR) in Russia and Deadhorse/Prudhoe Bay (D/PB) and Gakona $(\mathrm{G})$ in Alaska. The yellow line represents the generalized southern extent of the continuous permafrost zone.

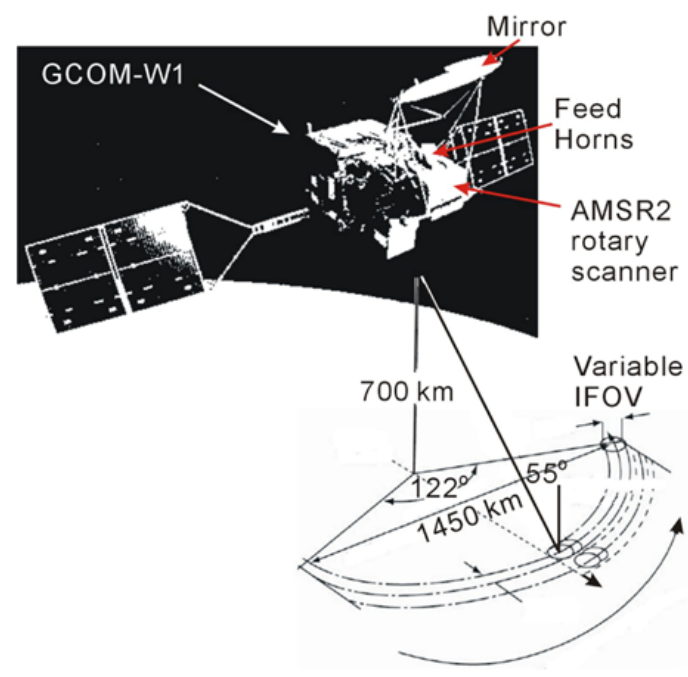

Figure 2. JAXA GCOM-W1 satellite and AMSR2 sensor illustrating earth surface scanning geometry.

AMSR2 is the follow-on passive microwave scanning radiometer developed by JAXA to supersede the capabilities and concepts of AMSR-E [22]. Improvements in antenna and radio design allow for smaller instantaneous field of view (24-by-42 km $10.65 \mathrm{GHz}$ channel compared to 29-by-51 km 10.65 GHz channel for AMSR-E, Table 1) and post-algorithm product gridding.

\subsection{NASA-Algorithm}

Soil moisturecontent (volumetric soil water content, skin-layer-one centimeter thickness) estimates are given inunit $\mathrm{g} / \mathrm{cm}^{3}$ by the NASA-algorithm and by the JAXA-algorithm for AMSR-E [23] [24]. The original "at launch" algorithm was a 6-channel $(6.925,10.65,18.70 \mathrm{GHz}$ in horizontal and vertical polarization) iterative forward inversion of radiation transfer functions of per-channel observed brightness temperature $\left(T_{B_{i}}^{\text {OBS }}\right)$ with 
Table 1. Summary characteristics of AMSR-E and AMSR2.

\begin{tabular}{cccc}
\hline Sensor/Satellite & Operation Period & Freq. (GHz) & IFOV (km) \\
& & & $75 \times 43(6.9 \mathrm{GHz})$ \\
& & & $51 \times 29(10.65 \mathrm{GHz})$ \\
AMSR-E $^{\circ}$ & June 2002 thru 4 Oct. 2011 & $6.925,10.65$, & $27 \times 16(18.7 \mathrm{GHz})$ \\
Aqua & Local 13:30 \& 01:30 ECT & $18.7,23.8$, & $32 \times 18(23.8 \mathrm{GHz})$ \\
& Acquisitions & $36.5,89.0$ & $14 \times 8(36.5 \mathrm{GHz})$ \\
& & (A, B) & $5 \times 4(89.0 \mathrm{GHz})$ \\
& & & $6 \times 4(89.0 \mathrm{GHz})$ \\
AMSR2 & June 2012 to current & $6.925 \& 7.3$, & $42 \times 24(10.65 \mathrm{GHz})$ \\
GCOM-W1 & Local 13:30 \& 01:30 ECT & $10.65,18.7$, & $22 \times 14(18.7 \mathrm{GHz})$ \\
& Acquisitions & $23.8,36.5,89.0$ & $12 \times 15(23.8 \mathrm{GHz})$ \\
& & & $5 \times 3(36.5 \mathrm{GHz})$ \\
& & & \\
& & & \\
& & & \\
& &
\end{tabular}

Instantaneous Field of View (IFOV), Equator Crossing Time (ECT), all channels have horizontal and vertical polarization.

dependence on surface emissivity and reflectivity to the geophysical retrieval parameter vector $\Phi_{i}(x)$ estimates of soil moisture $\left(m_{s}\right)$, vegetation water content $\left(w_{v}\right)$ and land-surface temperature $\left(T_{s}\right.$, a proxy for skin temperature) in a minimizing Chi-square process at grid points (i) given by

$$
\chi^{2}=\sum_{i=1}^{N}\left(\frac{T_{B_{i}}^{O B S}-\Phi_{i}(x)}{\sigma_{i}}\right)^{2}
$$

such that $x=\left\{m_{s}, w_{v}, T_{s}\right\}$ [25] [26]. Early post-launch saw high Radio Frequency Interference (RFI) at the $6.925 \mathrm{GHz}$ channel, which necessitated replacement by the $10.65 \mathrm{GHz}$ channel and furthermore necessitated usage of ancillary pre-existing datasets (look-up tables) to estimate $T_{s}$ and its sensitivity to modifying factors of polarization and soil moisture indices in an iterative correction scheme [27]-[29]. The ancillary look-up tables are global coarse resolution class-parameterizations of vegetation cover (generalized density and type), shallow (nominal 0 to $0.30 \mathrm{~m}$ depth) soil texture, ocean and large in-land water masks and landform classes (including frozen ground, mountainous terrain, permanent ice and perennial snow). AMSR-E Level-3 datasets are gridded in the equal-area Ease-grid projection system using a spheroid reference at 25-by-25 kilometer grid intervals [18]. We re-project these using the World Geodetic System (WGS) reference ellipsoid WGS-84. For Earth science applications the AMSR-E datasets employing the NASA-algorithm are archived at the National Snow and Ice Data Center, University of Colorado.

\subsection{JAXA-Algorithm for AMSR-E (Reprocessed) and AMSR2}

The JAXA-algorithmretains the iterative inversion forward radiation transfer functions for soil moisture and vegetation watercontent, emissivity and reflectivity from multi-channel brightness temperatures and polarization ratios as the current NASA-algorithm [22] [30]-[33]. Land-surface temperature from MODIS is utilized in the algorithm-retrieval instead of prescribed annual averaged global look-up table scheme. Vegetation roughness which was previously estimated by generalized vegetation type from course resolution global look-up tables, a modifier of vegetation water content that attenuates soil moisture is estimated from the 10.65 and $36.5 \mathrm{GHz}$ channels by incorporating a fractional coverage parameter from the Moderate Resolution Imaging Spectroradiometer (MODIS) Normalized Difference Vegetation Index (NDVI) 16-day composite indices and polarization index, an index of soil moisture from the channel brightness temperatures [30]. AMSR-E Level-3 reprocessed (JAXA archive) datasets are global daily grids in Geographic projection system at 0.25-by-0.25 degree ( 28-by$28 \mathrm{~km}$ ) with WGS-84 reference ellipsoid.

For the AMSR2 sensor JAXA has carried forward the algorithm development for reprocessing AMSR-E to process AMSR2 soil moisture content retrieval [22] [30] [31]. AMSR2 Level-3 global daily grids are in geographic projection at 0.25 -by- 0.25 degree $(\sim 28$-by-28 km) relative to WGS-84 in units of moisture volume fraction $\mathrm{m}^{3} / \mathrm{m}^{3}$ as a percentage. AMSR-E (reprocess) and AMSR2 datasets are archived by JAXA for the GCOM- 
W1 mission [14]. We use a dimensionless volume fraction vol./vol. for comparisons.

\section{Ground-Based Radio-Frequency Soil Moisture Measurements in Alaska and Russia}

In the late 1970 s the Trans-Alaska pipeline from Valdez $\left(146.3^{\circ} \mathrm{W}, 60.1^{\circ} \mathrm{N}\right)$ to Deadhorse/Prudhoe Bay $\left(148.5^{\circ} \mathrm{W}\right.$, $70.2^{\circ} \mathrm{N}$ ) and its access highways were constructed. Due to concern of possible effects from changing climate and from pipeline operations to underlying permafrost a project was undertaken to establish a series of boreholes instrumented to measure temperature and other geophysical parameters at depth from Fairbanks to Deadhorse, the north transect and to Gulkana, the south transect [34] [35]. In the late 1990s the sites of the boreholes were further instrumented for recording surface meteorological data and soil moisture at depths within the seasonal thaw layer, i.e. active-layer [36]-[38]. More recently the sites are being instrumented with autonomous operation Iridium Satellite Modems for remote data transmission to our laboratory offices at the Geophysical Institute, University of Alaska Fairbanks. In the period from late 1990s to present new sites for permafrost temperature monitoring at depth, active-layer soil moisture and surface meteorological data were established at other locations in Alaska, Canada, Central Asia, Nordic Regions and Russia [39]-[43]. We focus on a sub-set of sites featuring active-layer soil moisture measurements in Alaska and Russia, Figure 3 and Table 2.

Our soil moisture sensor at sites in Alaskais the Hydro Probe $\mathrm{II}^{1}$ [44] [45]. We deploy multiple sensorsat depths between $0.07 \mathrm{~m}$ to $1.0 \mathrm{~m}$ with Campbell data-loggers and batteries in containers on the ground and solarvoltaic panels above the surface. The Hydra Probe internal circuitry generates a 50-MHz signal (very high frequency radio) along two planar waveguides with four protruding tines (i.e. antennae) from the head for timedomain reflectometry based on empirical relationships of soil volumetric water content $\left(\theta, \mathrm{m}^{3} / \mathrm{m}^{3}\right)$ and dielectric permittivity $(\varepsilon)$

$$
\theta=-5.3 \times 10^{-2}+2.92 \times 10^{-2} \varepsilon_{c}-5.5 \times 10^{-4} \varepsilon_{c}^{2}+4.3 \times 10^{-6} \varepsilon_{c}^{3}
$$

such that for a two-phase (solid, liquid) system

$$
\varepsilon_{c}=\left(v_{1} \varepsilon_{1}^{\alpha}+v_{2} c_{2}^{\alpha}\right)^{1 / \alpha}
$$

where $\alpha$ takes values of -1 (electric field perpendicular to soil layering), 0.5 (isotropic) and +1 (electric field parallel to soil layering) and $\mathrm{c}$ is the electromagnetic wave velocity in the soil as given by

$$
c=\frac{1}{\varepsilon \mu^{1 / 2}} c_{0}
$$

where $c_{0}$ is the speed of light in vacuum, and $\mu$ is the relative magnetic permeability of the soil [46] [47]. The empirical relationship has been further generalized for a three-phase (soil, liquid and gas) and multi-component texture (clay, sand and silt).Outputs include complex dielectric constant, soil electrical conductivity, salinity, temperature $\left({ }^{\circ} \mathrm{C}\right)$ and volumetric water content. It is capable of functioning in saturated (including brine) soil environments (e.g. Barrow and West Dock sites). It can maintain accurate within $0.03 \mathrm{~m}^{3} / \mathrm{m}^{3}$ moisture values over a temperature range from $-30^{\circ} \mathrm{C}$ to $+40^{\circ} \mathrm{C}$ with site calibrations. Organic content can lead to a degradation of moisture measurement accuracy.

Our sites in Russia currently use the Onset S-SMC-M005 EC-5/ECH20 sensor operating at 70-MHz with two tines and capable of $0.03 \mathrm{~m}^{3} / \mathrm{m}^{3}$ measurement accuracy with site calibrations ${ }^{2}$. These sensors are based on timedomain reflectometry in [47]. Our sites include Hobo data-loggers with container batteries for remote operation and per-year visitation for data offloading.

The ground measurement comparisons with the retrieval algorithm values we use volume fraction vol./vol. in depths (per site) from 0.07 to $0.35 \mathrm{~m}$ (Table 3 and Table 4). Most of the probes are at shallow depths near 0.1 $\mathrm{m}$.

\section{Results and Discussion}

Our results of the daily comparisons by co-located microwave retrieval per NASA- and JAXA-algorithms with

\footnotetext{
${ }^{1}$ http://www.stevenswater.com/catalog/Product.aspx?SKU='93640'.

${ }^{2}$ http://www.onsetcomp.com/products/sensors/s-smc-m005.
} 

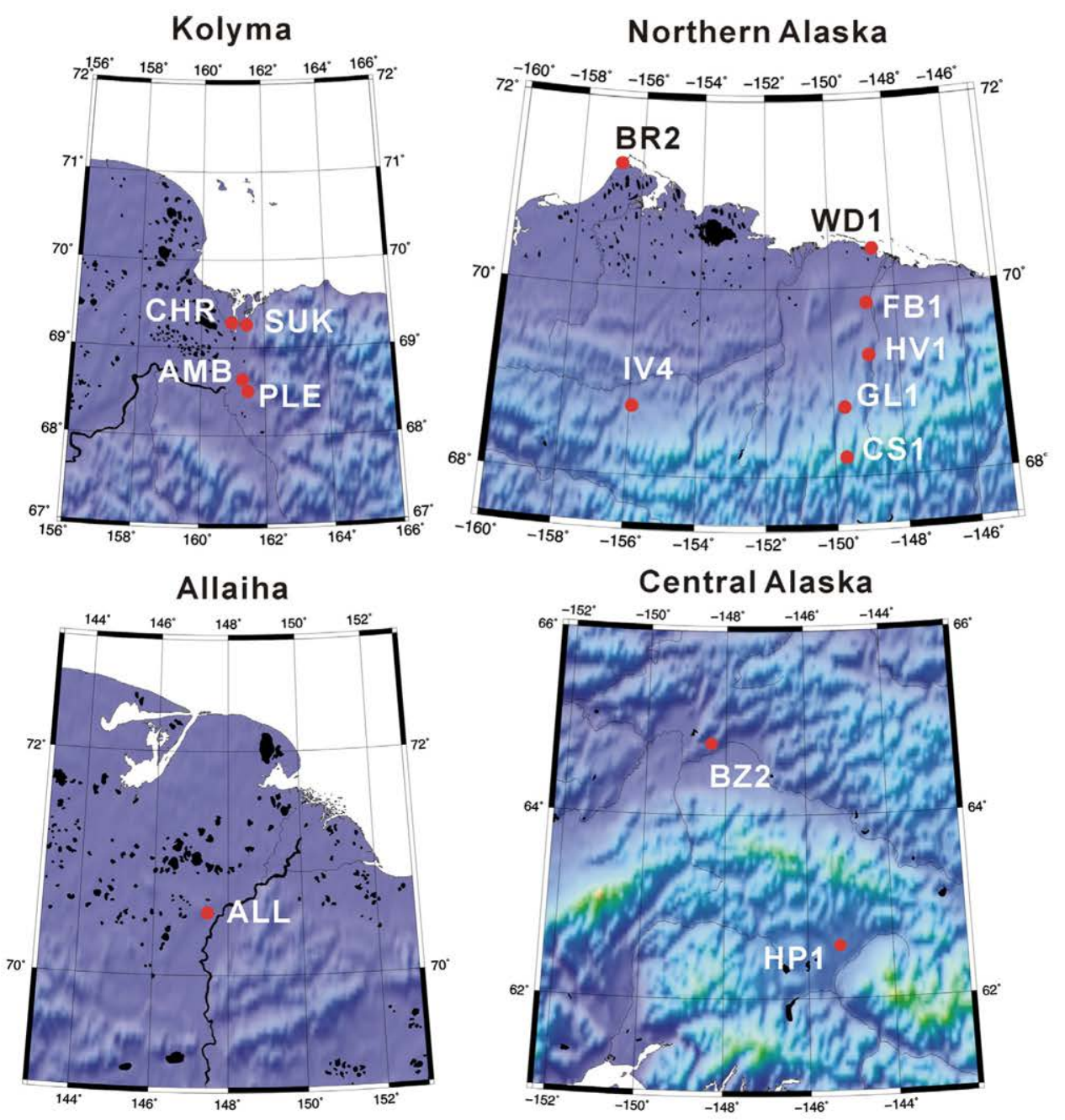

Bykovsky
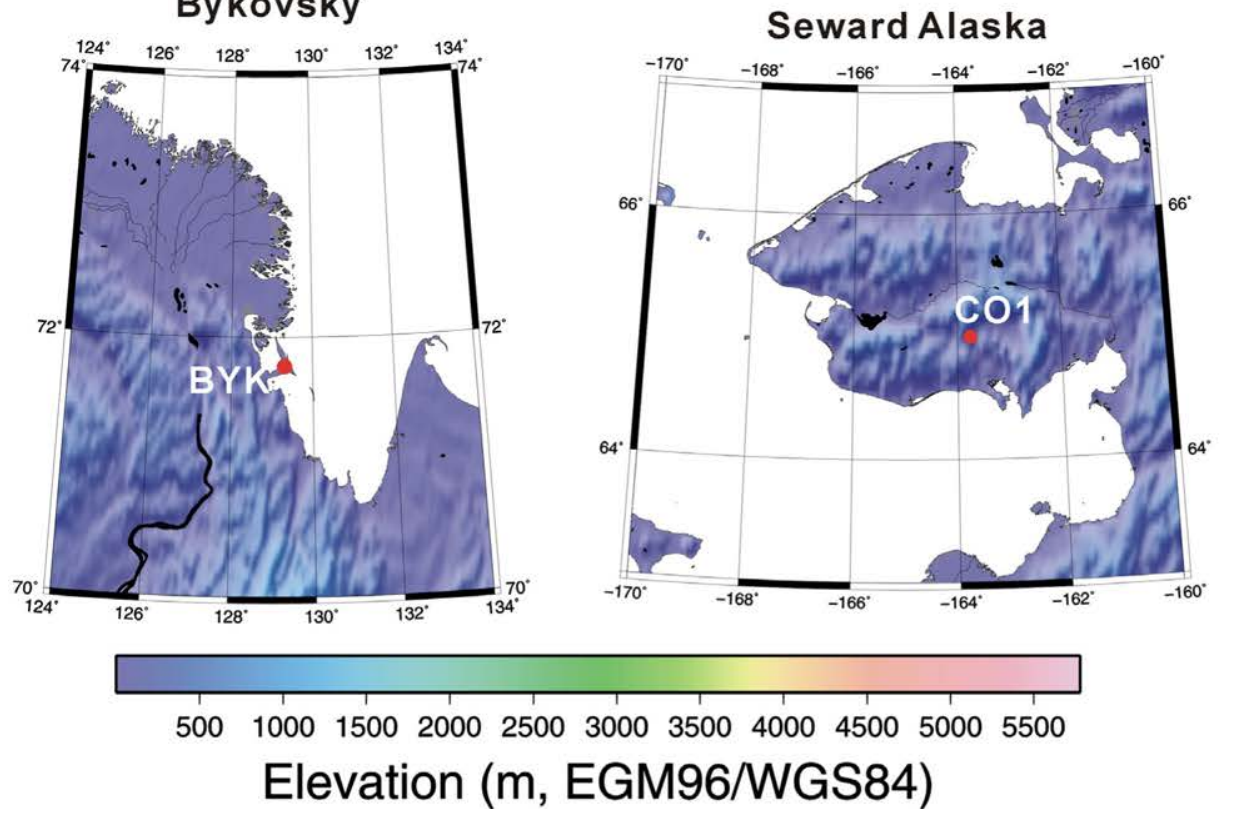

Figure 3. Digital elevation maps of soil water content sites in Alaska and Russia. 
Table 2. Ground-based radio frequency soil moisture sites in Alaska and Russia.

\begin{tabular}{|c|c|c|c|c|c|c|}
\hline Site & $\begin{array}{l}\text { Location Degrees } \\
\text { W, N WGS-84 }\end{array}$ & Code & Probe Depth (m) & $\begin{array}{c}\text { Texture }^{*} \\
\text { (Probe Type) }\end{array}$ & $\begin{array}{c}\text { At Depth Temperature } \\
\text { Range }\left({ }^{\circ} \mathrm{C}\right)\end{array}$ & Site Vegetation \\
\hline \multicolumn{7}{|l|}{ Alaska } \\
\hline Barrow & $\begin{array}{c}156.649331 \mathrm{~W} \\
71.320575 \mathrm{~N}\end{array}$ & BR2 & 0.10 & Clay (HP) & -26 to +12 & Coastal Tundra \\
\hline West Dock & $\begin{array}{c}148.552166 \mathrm{~W} \\
70.374467 \mathrm{~N}\end{array}$ & WD1 & 0.08 & Clay (HP) & -24 to +9 & Coastal Tundra \\
\hline Franklin Bluffs & $\begin{array}{c}148.721940 \mathrm{~W} \\
69.673888 \mathrm{~N}\end{array}$ & FB1 & 0.11 & Clay (HP) & -33 to +20 & $\begin{array}{c}\text { Lowland } \\
\text { Tundra/Grass }\end{array}$ \\
\hline Ivotuk & $\begin{array}{c}155.743743 \mathrm{~W} \\
68.480261 \mathrm{~N}\end{array}$ & IV4 & 0.16 & Clay (HP) & -16 to +13 & $\begin{array}{c}\text { Upland } \\
\text { Tundra/Shrub }\end{array}$ \\
\hline Happy Valley & $\begin{array}{c}148.848300 \mathrm{~W} \\
69.146640 \mathrm{~N}\end{array}$ & HV1 & 0.11 & Clay (HP) & -12 to +10 & Tundra \\
\hline Galbraith Lake & $\begin{array}{c}149.502416 \mathrm{~W} \\
68.477413 \mathrm{~N}\end{array}$ & GL1 & 0.14 & Clay (HP) & -20 to +12 & Upland Tundra \\
\hline Chandalar Shelf & $\begin{array}{c}149.580424 \mathrm{~W} \\
68.069068 \mathrm{~N}\end{array}$ & CS1 & 0.07 & Clay (HP) & -16 to +5 & $\begin{array}{c}\text { Upland } \\
\text { Tundra/Grass }\end{array}$ \\
\hline Council & $\begin{array}{c}163.738020 \mathrm{~W} \\
64.934821 \mathrm{~N}\end{array}$ & $\mathrm{CO} 1$ & 0.16 & Clay (HP) & -5 to +17 & Shrub/Grass \\
\hline Bonanza Creek & $\begin{array}{c}148.288546 \mathrm{~W} \\
64.714997 \mathrm{~N}\end{array}$ & BZ2 & 0.19 & Clay (HP) & -8 to +13 & Boreal Forest/Shrub \\
\hline HAARP & $\begin{array}{c}145.145277 \mathrm{~W} \\
62.392916 \mathrm{~N}\end{array}$ & HP1 & 0.35 & Clay (HP) & -7 to +3 & Boreal Forest/Shrub \\
\hline \multicolumn{7}{|l|}{ Russia } \\
\hline Bykovsky & $\begin{array}{l}129.356292 \mathrm{E} \\
71.742466 \mathrm{~N}\end{array}$ & BYK & 0.15 & SLO (EC) & -27 to +2 & Coastal Tundra \\
\hline Sukharna & $\begin{array}{l}161.823729 \mathrm{E} \\
69.487562 \mathrm{~N}\end{array}$ & SUK & 0.20 & SLO (EC) & -31 to +9 & $\begin{array}{l}\text { Coastal Tundra } \\
\text { Floodplain }\end{array}$ \\
\hline Allaiha & $\begin{array}{l}147.442000 \mathrm{E} \\
70.560300 \mathrm{~N}\end{array}$ & ALL & 0.10 & SLO (EC) & -26 to +8 & $\begin{array}{c}\text { Lowland } \\
\text { Tundra/Shrub }\end{array}$ \\
\hline Cherskii & $\begin{array}{l}161.315816 \mathrm{E} \\
68.755489 \mathrm{~N}\end{array}$ & CHR & 0.12 & Clay (HP) & -11 to +12 & Boreal Forest/Shrub \\
\hline Amboliha & $\begin{array}{l}161.391950 \mathrm{E} \\
68.638934 \mathrm{~N}\end{array}$ & AMB & 0.10 & SLO (EC) & -14 to +10 & Boreal Floodplain \\
\hline Pleistocene Park & $\begin{array}{l}161.493507 \mathrm{E} \\
68.511583 \mathrm{~N}\end{array}$ & PLE & 0.10 & SLO (EC) & -13 to +8 & Boreal Upland Shrub \\
\hline
\end{tabular}

${ }^{*}$ Hydra Probe (HP) lab-calibration temperature and post processing texture, ECH2O (EC) in-situ calibration with soil and temperature. Silt Loam \& Organics (SLO).

the VHF sub-surface probe measurements per station are illustrated in Figures 4-8 time-series and co-location correlation plots and Figure 9 and Figure 10 maps of spatial trends of retrieval soil moisture content in western North America and Tables 3-5. We will first examine the comparisons on a site-by-site daily basis that will be followed by summaries of findings. 
Table 3. Comparisons of soil moisture content at Alaska and Russia sites by VHF-Probe measurements and JAXA and NASA AMSR-E retrieval algorithms.

\begin{tabular}{|c|c|c|c|c|c|c|c|c|}
\hline & $\begin{array}{c}\text { Probe } \\
\text { Thaw Range } \\
\text { vol./vol. }\end{array}$ & $\begin{array}{c}\text { Probe Thaw } \\
\text { Season Ave. } \\
\text { vol./vol. }\end{array}$ & $\begin{array}{c}\text { JAXA- } \\
\text { Retrieval } \\
\text { Range vol./vol. }\end{array}$ & $\begin{array}{c}\text { JAXA- } \\
\text { Retrieval Ave. } \\
\text { vol./vol. 13:30 }\end{array}$ & $\begin{array}{c}\text { JAXA- } \\
\text { Retrieval Ave. } \\
\text { vol./vol. 01:30 }\end{array}$ & $\begin{array}{c}\text { NASA- } \\
\text { Retrieval } \\
\text { Range vol./vol. }\end{array}$ & $\begin{array}{l}\text { NASA- } \\
\text { Retrieval Ave. } \\
\text { vol./vol. 13:30 }\end{array}$ & $\begin{array}{c}\text { NASA- } \\
\text { Retrieval Ave. } \\
\text { vol./vol. 01:30 }\end{array}$ \\
\hline Barrow & 0 to 0.40 & $0.40(0.03)$ & 0.02 to 0.60 & $0.52(0.13)$ & $0.51(0.14)$ & 0.1 to 0.3 & $0.12(0.05)$ & $0.11(0.05)$ \\
\hline West Dock & 0 to 0.45 & $0.45(0.01)$ & 0.02 to 0.60 & $0.43(0.12)$ & $0.46(0.09)$ & 0.1 to 0.3 & $0.13(0.05)$ & $0.12(0.04)$ \\
\hline Bykovsky & 0 to 0.27 & $0.25(0.01)$ & 0.18 to 0.60 & $0.43(0.11)$ & $0.39(0.13)$ & 0.1 to 0.2 & $0.17(0.03)$ & $0.15(0.03)$ \\
\hline Franklin B. & 0 to 0.51 & $0.44(0.03)$ & 0.02 to 0.38 & $0.09(0.03)$ & $0.06(0.02)$ & 0.1 to 0.36 & $0.14(0.05)$ & $0.12(0.04)$ \\
\hline Happy V. & 0 to 0.40 & $0.35(0.04)$ & 0.02 to 0.57 & $0.06(0.06)$ & $0.04(0.03)$ & 0.2 to 0.47 & $0.18(0.05)$ & $0.16(0.04)$ \\
\hline Galbraith L. & 0 to 0.62 & $0.58(0.02)$ & 0.01 to 0.40 & $0.05(0.03)$ & $0.29(0.01)$ & 0.1 to 0.43 & $0.18(0.03)$ & $0.17(0.03)$ \\
\hline Allaiha & 0 to 0.26 & $0.25(0.01)$ & 0.11 to 0.49 & $0.28(0.14)$ & $0.18(0.12)$ & 0.2 to 0.3 & $0.21(0.05)$ & $0.2(0.04)$ \\
\hline Cherskii & 0 to 0.40 & $0.40(0.01)$ & 0.02 to 0.40 & $0.08(0.05)$ & $0.08(0.05)$ & 0.1 to 0.2 & $0.06(0.03)$ & $0.08(0.03)$ \\
\hline Ivotuk & 0 to 0.88 & $0.72(0.09)$ & 0.02 to 0.59 & $0.08(0.09)$ & $0.05(0.05)$ & 0.2 to 0.47 & $0.16(0.03)$ & $0.16(0.03)$ \\
\hline Chandalar S. & 0 to 0.96 & $0.75(0.15)$ & 0.01 to 0.38 & $0.05(0.03)$ & $0.04(0.02)$ & 0.1 to 0.34 & $0.15(0.02)$ & $0.16(0.02)$ \\
\hline Council & 0.1 to 0.62 & $0.42(0.04)$ & 0.02 to 0.56 & $0.11(0.12)$ & $0.09(0.10)$ & 0.1 to 0.38 & $0.14(0.03)$ & $0.14(0.02)$ \\
\hline Bonanza C. & 0.1 to 0.40 & $0.38(0.02)$ & 0.04 to 0.59 & $0.17(0.16)$ & $0.16(0.18)$ & 0.1 to 0.29 & $0.14(0.02)$ & $0.14(0.01)$ \\
\hline HAARP & 0 to 0.53 & $0.42(0.02)$ & 0.04 to 0.59 & $0.12(0.11)$ & $0.11(0.13)$ & 0.1 to 0.26 & $0.13(0.02)$ & $0.13(0.01)$ \\
\hline
\end{tabular}

Table 4. Comparisons of soil moisture content at Alaska and Russia sites by VHF-probe measurements and JAXA AMSR2 retrieval algorithm.

\begin{tabular}{|c|c|c|c|c|c|}
\hline & $\begin{array}{c}\text { Probe Thaw Range } \\
\text { vol./vol. }\end{array}$ & $\begin{array}{c}\text { Probe Thaw Season } \\
\text { Ave. vol./vol. }\end{array}$ & $\begin{array}{c}\text { JAXA-Retrieval } \\
\text { Range vol./vol. }\end{array}$ & $\begin{array}{c}\text { JAXA-Retrieval } \\
\text { Ave. vol./vol. 13:30 }\end{array}$ & $\begin{array}{c}\text { JAXA-Retrieval } \\
\text { Ave. vol./vol. 01:30 }\end{array}$ \\
\hline Barrow & 0 to 0.40 & $0.39(0.03)$ & 0.04 to 0.60 & $0.22(0.09)$ & $0.22(0.12)$ \\
\hline West Dock & 0 to 0.45 & $0.45(0.01)$ & 0.02 to 0.60 & $0.33(0.12)$ & $0.10(0.05)$ \\
\hline Bykovsky & 0 to 0.27 & $0.25(0.01)$ & 0.10 to 0.60 & $0.32(0.16)$ & $0.31(0.14)$ \\
\hline Sukharna & 0 to 0.31 & $0.24(0.02)$ & 0.02 to 0.60 & $0.39(0.17)$ & $0.26(0.15)$ \\
\hline Franklin B. & 0 to 0.51 & $0.44(0.03)$ & 0.02 to 0.37 & $0.14(0.05)$ & $0.07(0.03)$ \\
\hline Happy V. & 0 to 0.40 & $0.35(0.04)$ & 0.02 to 0.27 & $0.09(0.04)$ & $0.06(0.03)$ \\
\hline Galbraith L. & 0 to 0.62 & $0.58(0.02)$ & 0.02 to 0.22 & $0.06(0.02)$ & $0.06(0.03)$ \\
\hline Allaiha & 0 to 0.26 & $0.25(0.01)$ & 0.09 to 0.59 & $0.28(0.14)$ & $0.18(0.13)$ \\
\hline Amboliha & 0 to 0.24 & $0.24(0.01)$ & 0.02 to 0.59 & $0.20(0.12)$ & $0.23(0.16)$ \\
\hline Pleistocene Park & 0 to 0.43 & $0.15(0.08)$ & 0.02 to 0.60 & $0.18(0.11)$ & $0.16(0.11)$ \\
\hline Ivotuk & 0 to 0.88 & $0.72(0.09)$ & 0.02 to 0.44 & $0.09(0.06)$ & $0.09(0.07)$ \\
\hline Chandalar S. & 0 to 0.88 & $0.75(0.15)$ & 0.01 to 0.16 & $0.07(0.02)$ & $0.06(0.03)$ \\
\hline Council & 0.1 to 0.51 & $0.41(0.07)$ & 0.02 to 0.52 & $0.12(0.09)$ & $0.11(0.08)$ \\
\hline Bonanza C. & 0.1 to 0.40 & $0.38(0.08)$ & 0.02 to 0.79 & $0.33(0.17)$ & $0.32(0.18)$ \\
\hline HAARP & 0 to 0.46 & $0.43(0.06)$ & 0.01 to 0.58 & $0.25(0.13)$ & $0.26(0.14)$ \\
\hline
\end{tabular}

Standard deviations are given in parentheses. 


\section{Alaska Sites}
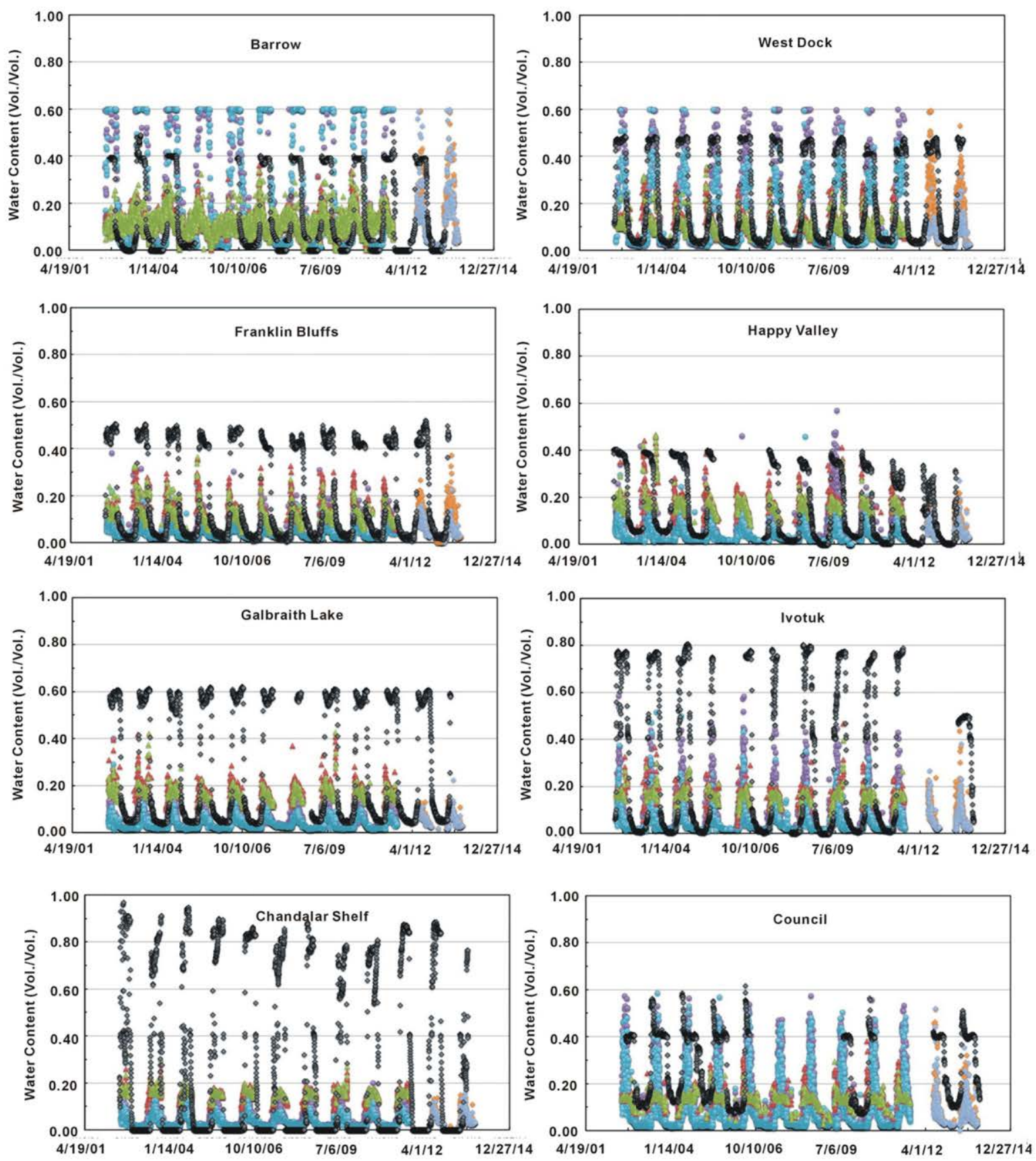

Legend

$\checkmark$ Probe Daily

$\triangle$ AMSRE 13:30 ECT NASA Algorithm

$\triangle$ AMSRE 01:30 ECT NASA Algorithm

- AMSRE 13:30 ECT JAXA Algorithm

- AMSRE 01:30 ECT JAXA Algorithm

- AMSR2 13:30 ECT JAXA Algorithm

- AMSR2 01:30 ECT JAXA Algorithm 
Alaska Sites Continued
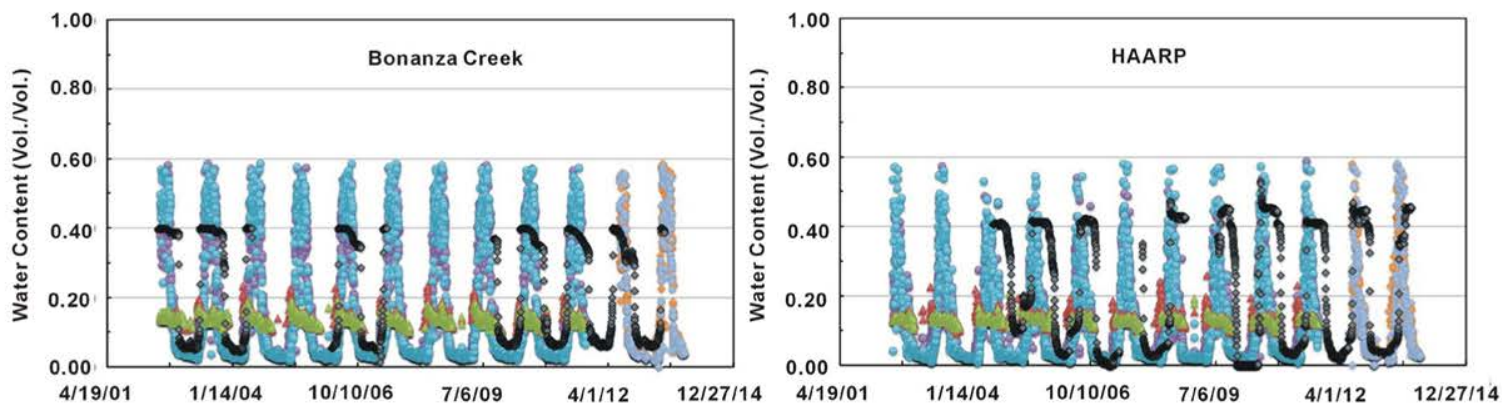

\section{Russia Sites}
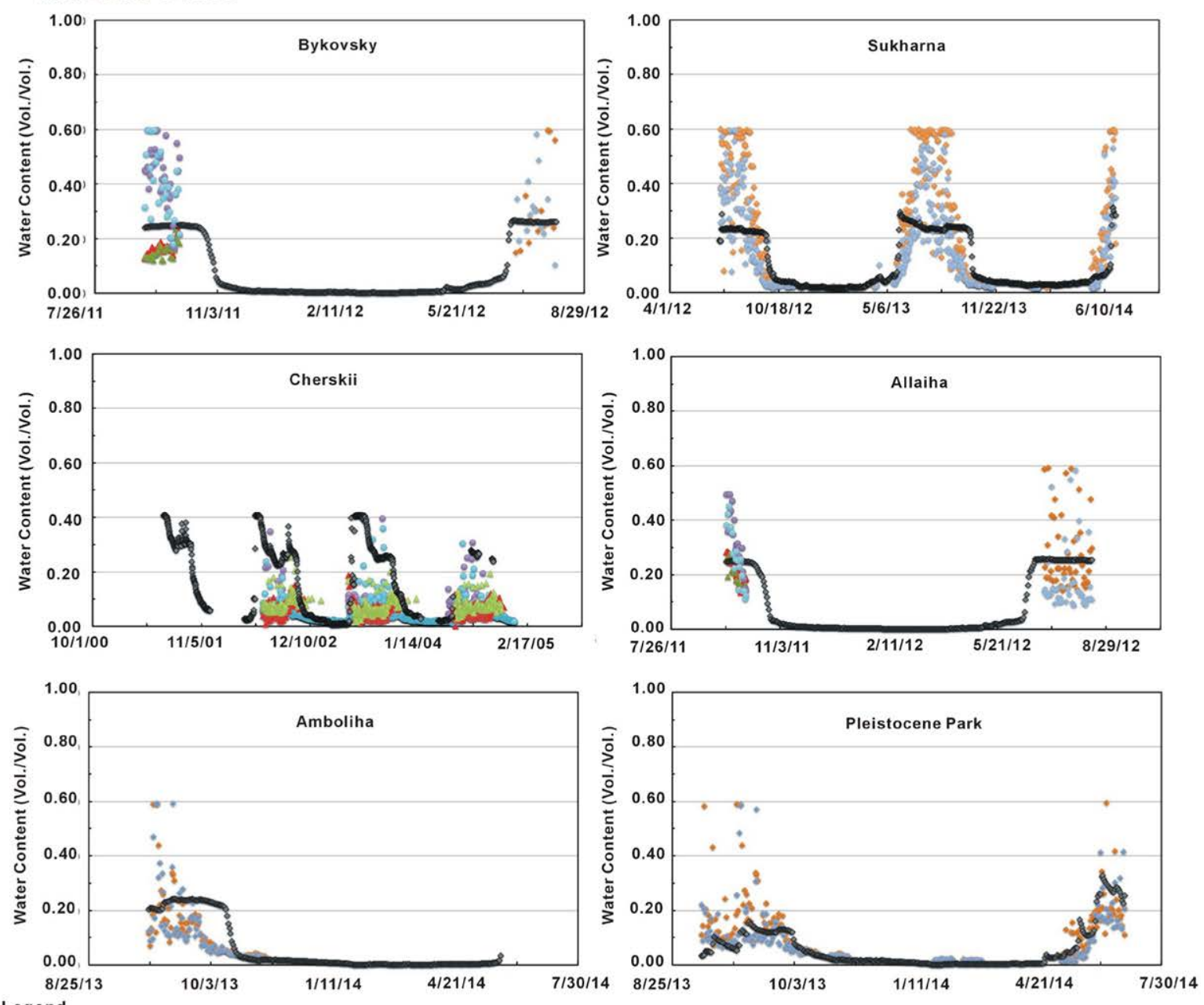

Legend

- Probe Daily

$\triangle$ AMSRE 13:30 ECT NASA Algorithm

$\triangle$ AMSRE 01:30 ECT NASA Algorithm

- AMSRE 13:30 ECT JAXA Algorithm

- AMSRE 01:30 ECT JAXA Algorithm

- AMSR2 13:30 ECT JAXA Algorithm

- AMSR2 01:30 ECT JAXA Algorithm

(b)

Figure 4. (a) Daily time series comparisons of soil moisture contents at sites in Alaska and Russia by ground measurement and NASA- and JAXA-algorithm retrievals; (b) Daily time series comparisons of soil moisture contents at sites in Alaska and Russia by measurement and NASA- and JAXA-algorithm retrievals. 


\section{Alaska Sites}
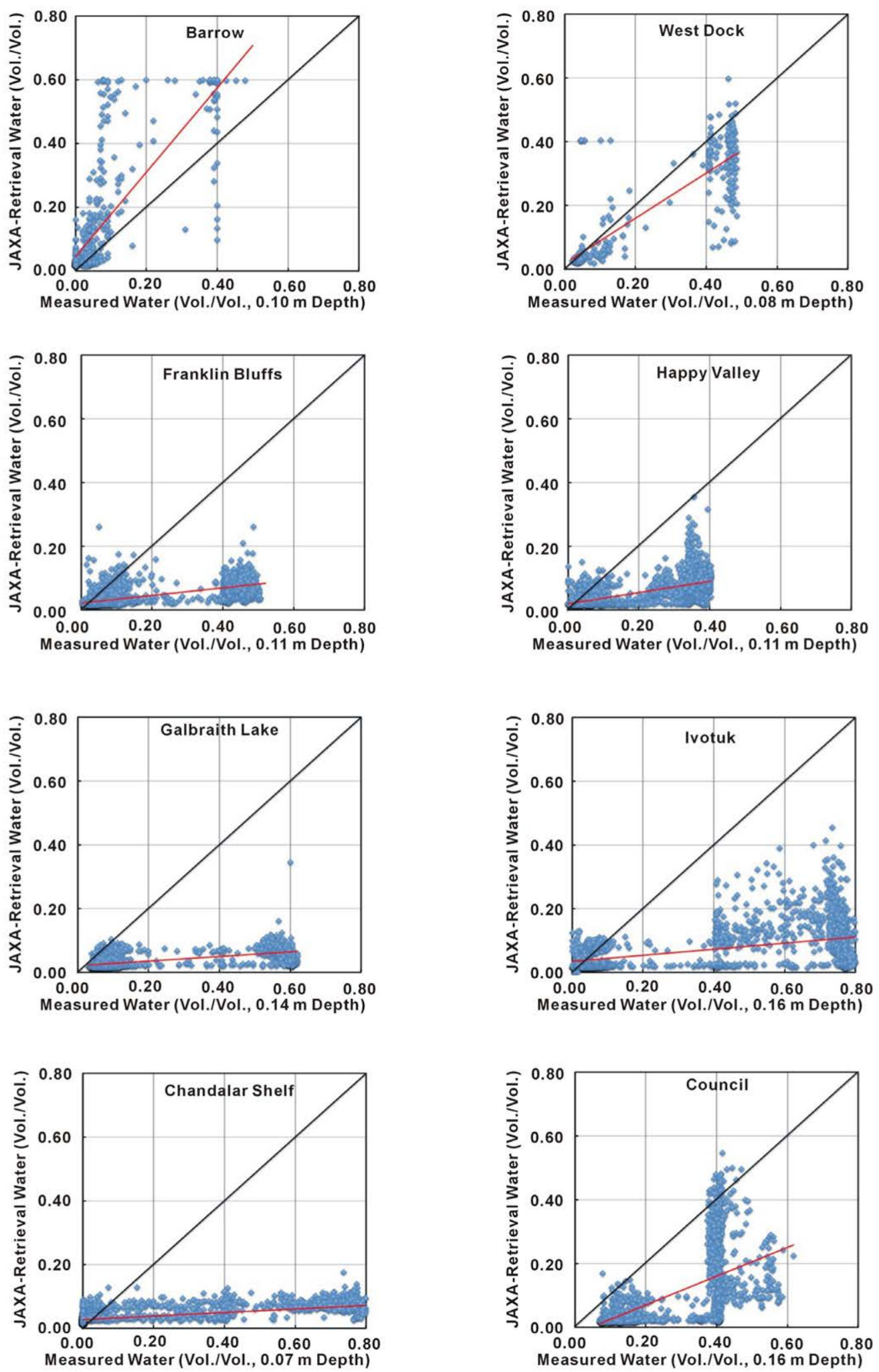

(a) 


\section{Alaska Sites Continued}
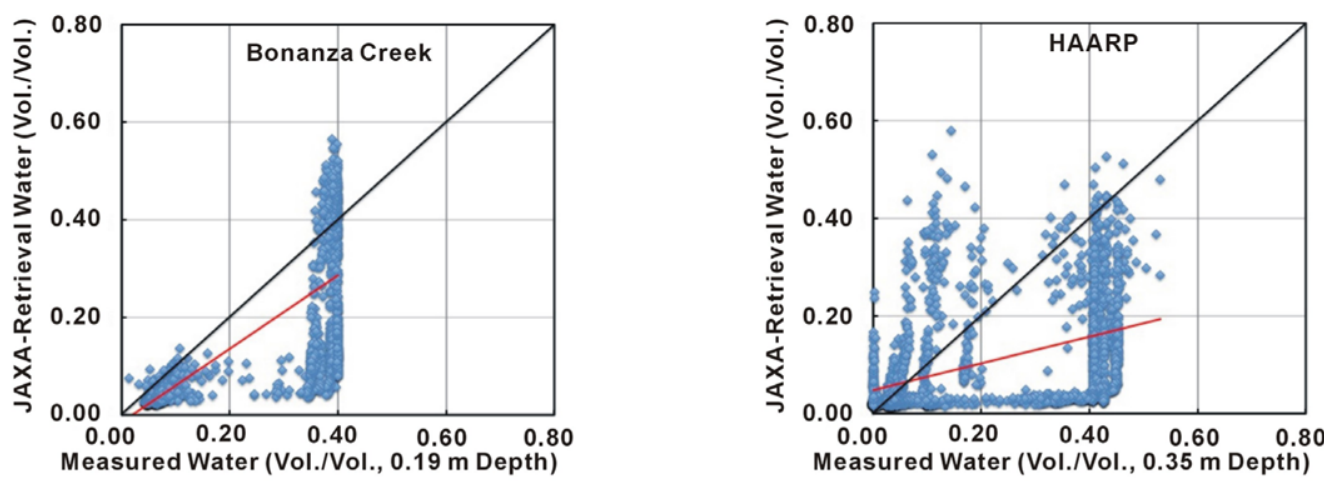

\section{Russia Sites}
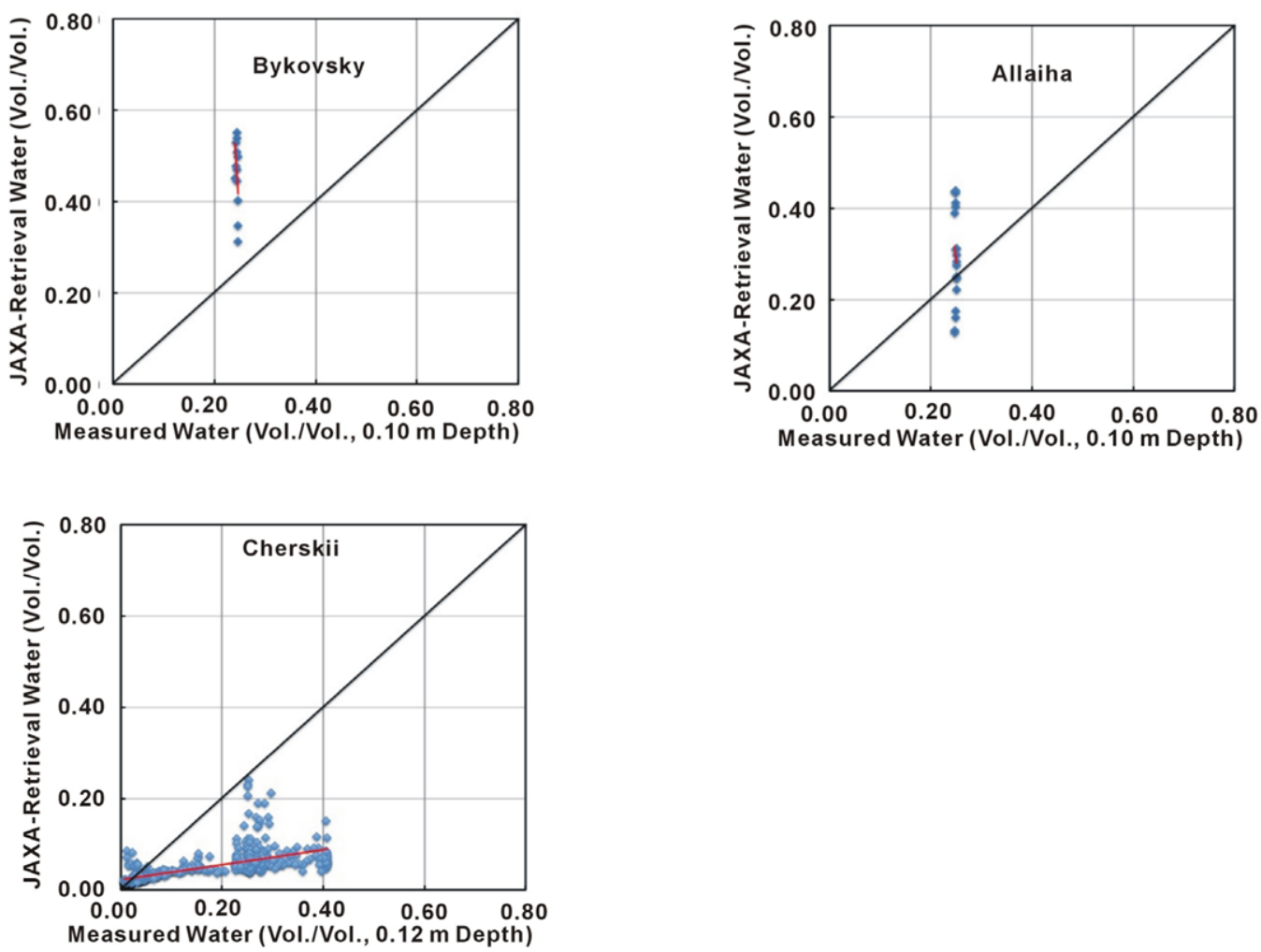

(b)

Figure 5. (a) Colocation-time plots of measured soil moisture content with JAXA-algorithm retrievals from AMSR-E for sites in Alaska and Russia sites. Time-range for measured soil moisture content is daily (24 hour) average, for retrievals is day-ECT (13:30 local and 01:30 local); (b) Colocation-time plots of measured soil moisture content with JAXA-algorithm retrievals from AMSR-E for sites in Alaska and Russia sites. Time-range for measured soil moisture content is daily (24 hour) average, for retrievals is day-ECT (13:30 local and 01:30 local).

\subsection{Sites Nearest the Arctic Ocean in Alaska and Russia}

Our sites within 1 to $5 \mathrm{~km}$ of the Arctic Ocean are within the coastal tundra of the continuous permafrost zone at Barrow and West Dock in Alaska, and at Bykovsky and Sukharna in Russia, Figure 4(a) (Barrow and West Dock) and Figure 4(b) (Bykovsky and Sukharna), respectively. Vegetation consists of mosses and dense-grass tussock 


\section{Alaska Sites}
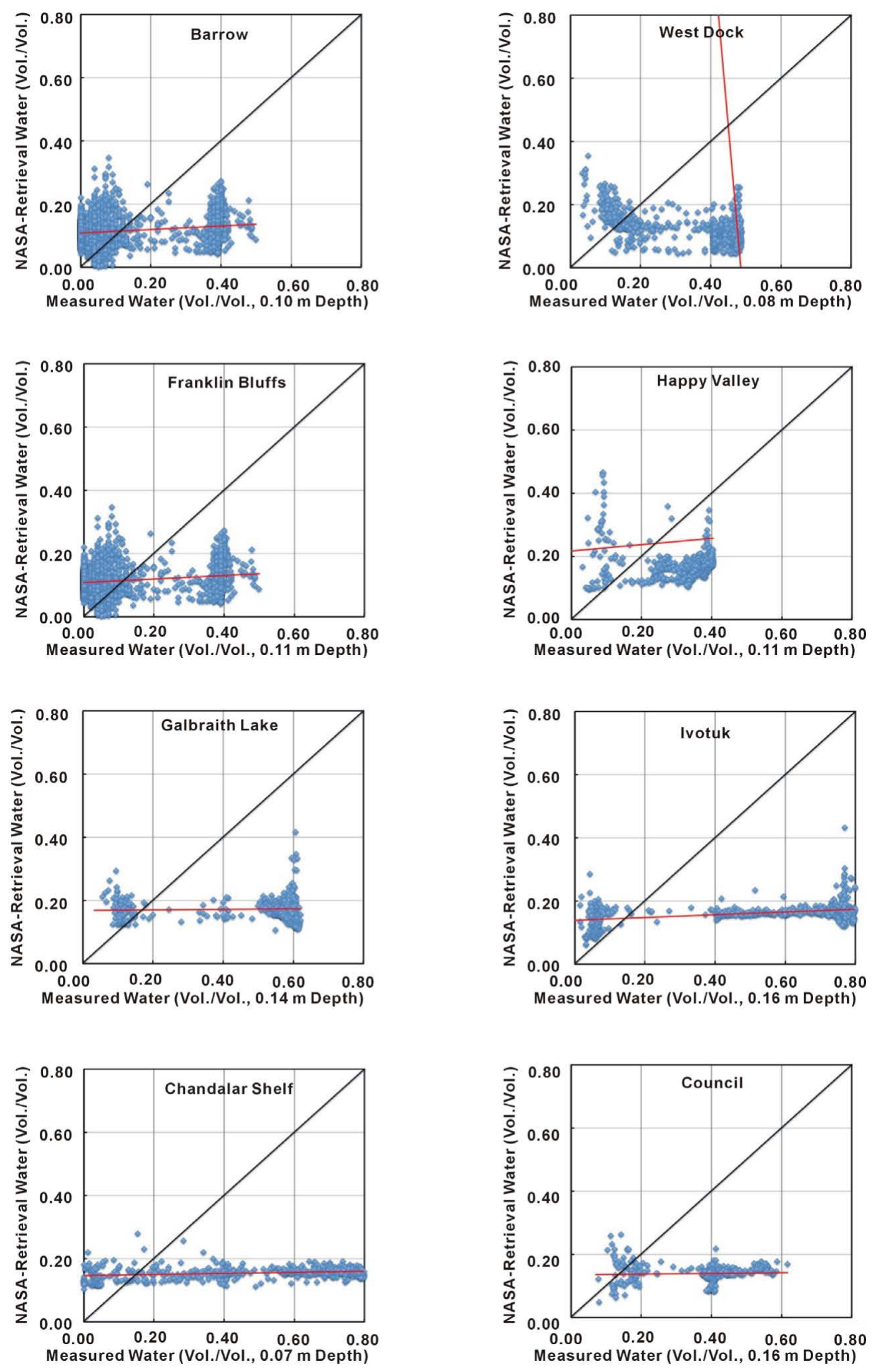

(a) 


\section{Alaska Sites Continued}
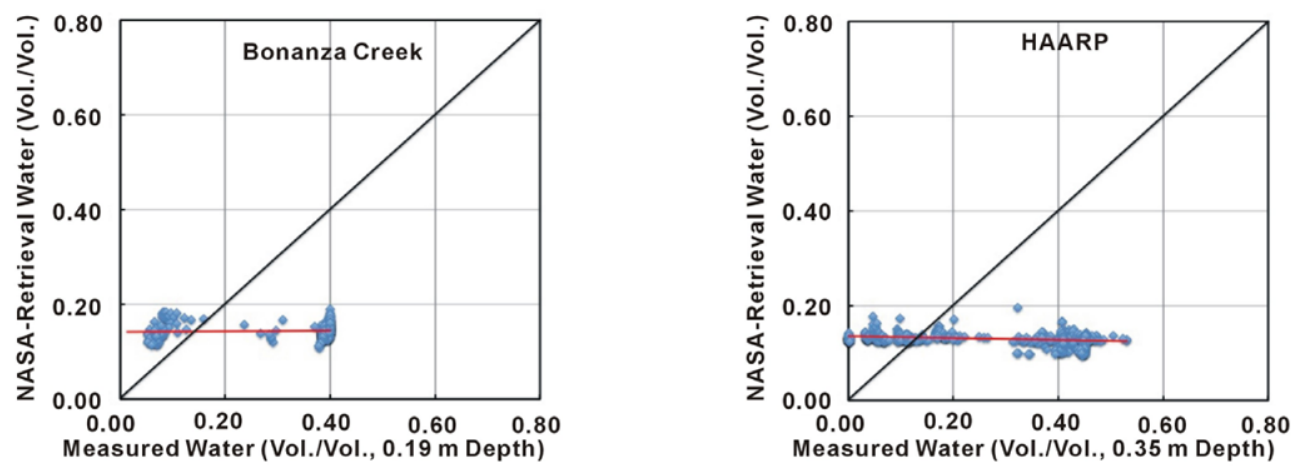

\section{Russia Sites}
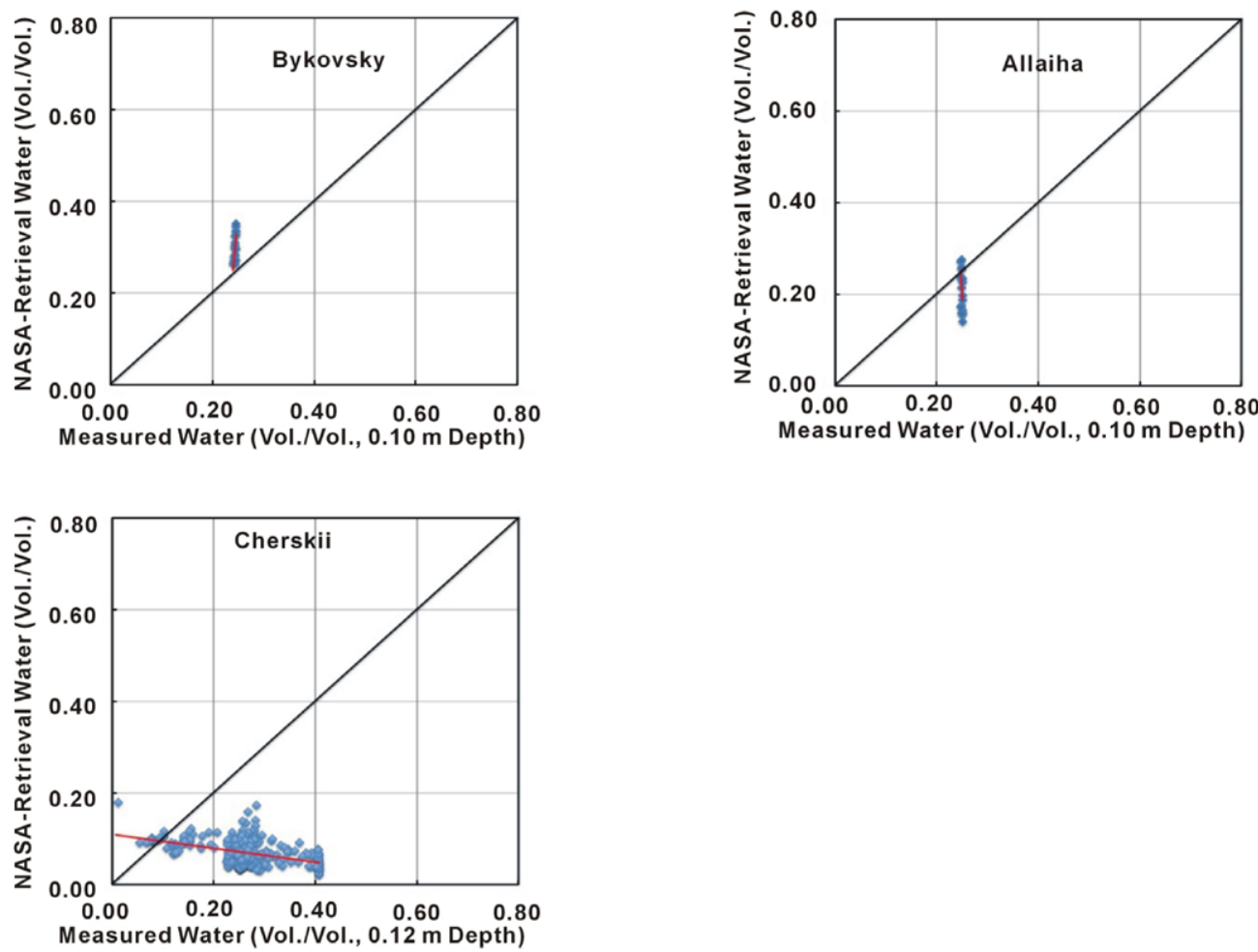

(b)

Figure 6. (a) Colocation-time plots of measured soil moisture content with NASA-algorithm retrievals from AMSR-E for sites in Alaska and Russia sites. Time-range for measured soil moisture content is daily (24 hour) average, for retrievals is day-ECT (13:30 local and 01:30 local). (b) Colocation-time plots of measured soil moisture content with NASA-algorithm retrievals from AMSR-E for sites in Alaska and Russia sites. Time-range for measured soil moisture content is daily (24 hour) average, for retrievals is day-ECT (13:30 local and 01:30 local).

1 to $5 \mathrm{~cm}$ in height in the summer season. During summer the space between the dense-grass tops and the mineral-organic soil surface can be covered with standing water (Arctic wetlands).

Daily time series illustrate the remote-sensing microwave-based NASA- and JAXA-algorithmic retrieval soil moisture content performance relative to our VHF-probe sub-surface measurements.

The VHF-probes at $0.10 \mathrm{~m}$ depth (Figure 4(a), Barrow), $0.08 \mathrm{~m}$ depth (Figure 4(a), West Dock), $0.15 \mathrm{~m}$ 
depth (Figure 4(b), Bykovsky) and $0.20 \mathrm{~m}$ depth (Figure 4(b), Sukharna) all show a seasonal cycle of thawing beginning in April reaching a fully thawed state in June followed by freezing in late August. Soil moisture content measurements are near 0 vol./vol. (frozen) in April rising to near 0.40 vol./vol. (thawed) at Barrow, near 0.45 vol./vol. at West Dock, near 0.27 vol./vol. at Bykovsky and near 0.31 vol./vol. at Sukharna, in June. The variation of soil moisture content per-site is due to differences soil texture and organic material. Organic material is not accounted for in our calibrations of the VHF-probes.

Daily AMSR-E NASA-algorithm retrievals show no change of freeze-thaw state, although they show a cyclical variation from soil moisture content of 0.1 to 0.3 vol./vol., on-average (Figure 4(a), Barrow and West Dock, Figure 4(b), Bykovsky and Sukharna, respectively). The peak retrieval soil moisture content occurs during lateMay into early-June. This is followed by a decrease in retrieval soil moisture content on through July, giving the daily 13:30 and 01:30 ECT time-series a punctuated cyclical response. June 2002 to October 2011 NASA-algorithm retrieval average soil moisture content is 0.12 (13:30 ECT) and 0.11 vol./vol. (01:30 ECT) with standard deviations of 0.05 vol./vol. at Barrow, 0.13 (13:30 ECT) and 0.12 vol./vol. (01:30 ECT) with standard deviation of 0.05 and 0.04 vol./vol. at West Dock, 0.17 (13:30 ECT) and 0.15 vol./vol. (01:30 ECT) with standard deviations of 0.03 vol./vol. at Bykovsky, respectively.

Daily AMSR-E JAXA-algorithm retrievals show change of freeze-thaw state that in most cases corresponds with our VHF-probe measurements on a daily basis (Figure 4(a), Barrow and West Dock, Figure 4(b), Bykovsky and Sukharna, respectively). On a season-average basis the closest correspondence occurs at West Dock. JAXA-algorithm retrieval averages over-perform relative to the VHF-probe averages at Barrow and Bykovsky. June/July retrieval maxima are near 0.6 vol./vol. at these sites.

Daily AMSR2 JAXA-algorithm retrievals at these sites show seasonality and similar characteristics to the AMSR-E JAXA-algorithm retrievals at Barrow (Figure 4(a)). The VHF-probe ranges in soil moisture content are much the same over the period of one season a previous. At Sukharna (Figure 4(b)) with a depth of $0.20 \mathrm{~m}$ the seasonal range in soil moisture content is from 0 to $0.31 \mathrm{vol} . / \mathrm{vol}$. with a thaw season average of $0.24 \mathrm{vol} . / \mathrm{vol}$. and standard deviation of 0.02 vol./vol. and similar to Bykovsky. The AMSR2 JAXA-algorithm retrieval thaw season range is 0.02 to $0.60 \mathrm{vol} . / \mathrm{vol}$. with averages of 0.39 (13:30 ECT) and 0.26 (01:30 ECT) vol./vol. with standard deviations of 0.17 and 0.15 vol./vol., respectively.

Co-location and co-time comparisons Figure 5(a) (Barrow and West Dock) and Figure 5(b) (Bykovsky and Sukharna) and Table 5 show the AMSR-E JAXA-algorithm retrieval versus measurement site $\mathrm{R}^{2}$ with the highest values, though significance is modest. The AMSR-E NASA-algorithm retrieval versus measurement sites $\mathrm{R}^{2}$ have the lowest values and, not significant (Figure 6(a) and Figure 6(b) and Table 5). This scoring by $\mathrm{R}^{2}$ does indicate that the AMSR-E JAXA-algorithm is significantly different relative to the AMSR-E NASA-algorithm (Figure 7(a) and Figure 7(b) and Table 5). The AMSR2 JAXA-algorithm retrievals versus measurement site $\mathrm{R}^{2}$ scores are similar to the AMSR-E JAXA scores, and of modest significance (Figure 8(a) and Figure 8(b) and Table 5).

\subsection{Arctic Coastal Plain and Foothills Sites, Alaska and Low-Land Sites Russia}

Our sites Franklin Bluffs, Happy Valley and Galbraith Lake cross the Arctic coastal plain and Foothills also within the continuous permafrost zone, a region of short height vegetation of lowland-wetland to up-land tundra zones (Figure 4(a), Franklin Bluffs, Happy Valley and Galbraith Lake, respectively, and Table 4). During the short-summer thaw season our VHF-probe soil moisture contents show bimodality at each site. At Franklin Bluffs (Coastal Plain, low relief except for the Bluffs about $2 \mathrm{~km}$ east across the Sagavanirktok River and floodplain, Figure 4(a), Franklin Bluffs) the thaw season average soil moisture content is near 0.44 vol./vol., standard deviation of 0.03 vol./vol. at $0.11 \mathrm{~m}$ depth with early June and August modes up to 0.51 vol./vol. in most years. At Happy Valley (lower Foothills, moderate relief, Figure 4(a), Happy Valley) the average soil moisture content is near 0.35 vol./vol., standard deviation of 0.04 vol./vol. at $0.11 \mathrm{~m}$ depth in a range of 0 to $0.40 \mathrm{vol} . / \mathrm{vol}$. with the last 3-years data showing a decline relative to the remainder of the series. Galbraith Lake (upper Foothills, glacial valley north-facing from the Brooks Range, Figure 4(a), Galbraith Lake) shows thaw season average soil moisture content near $0.58 \mathrm{vol} . / \mathrm{vol}$., standard deviation of $0.02 \mathrm{vol} . / \mathrm{vol}$. at $0.14 \mathrm{~m}$ depth and modes up to 0.62 vol./vol. in early June and August. The relative higher soil moisture content values at Galbraith Lake are in part an orographic effect on precipitation (Arctic Ocean source) by the Brooks Range.

The daily AMSR-E NASA-algorithm retrievals at the Coastal Plain and Foothills sites do not show freeze- 


\section{Alaska Sites}
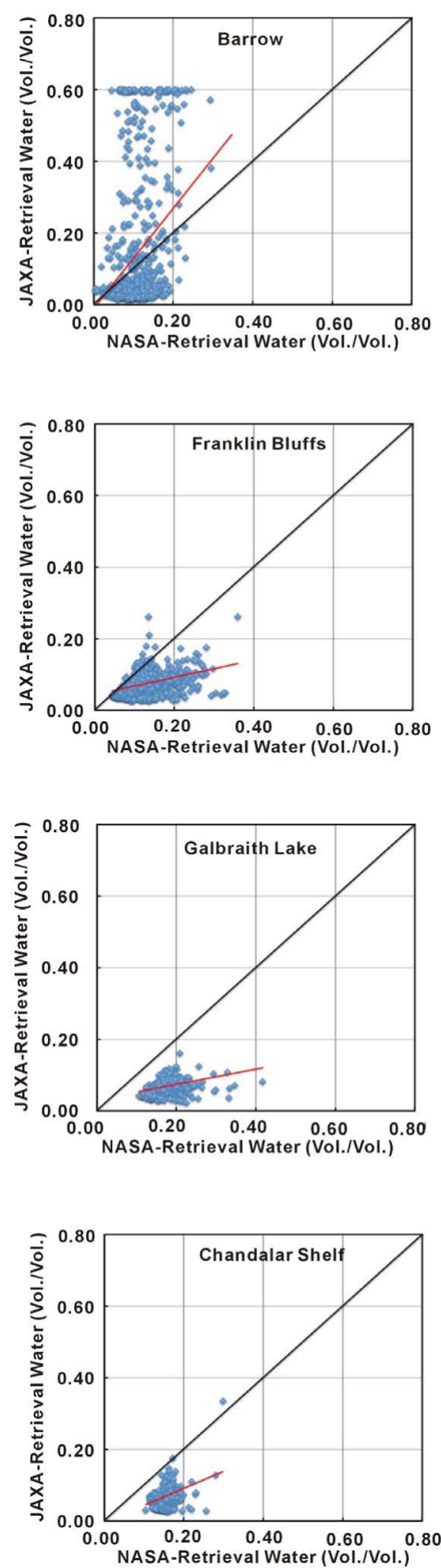
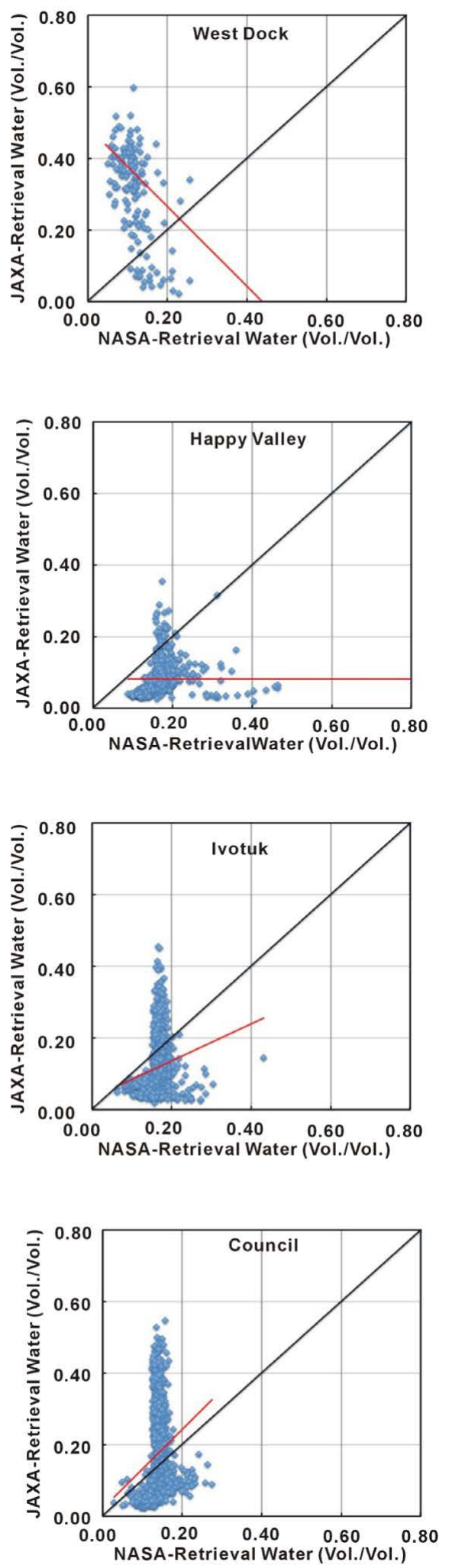

(a) 


\section{Alaska Sites Continued}

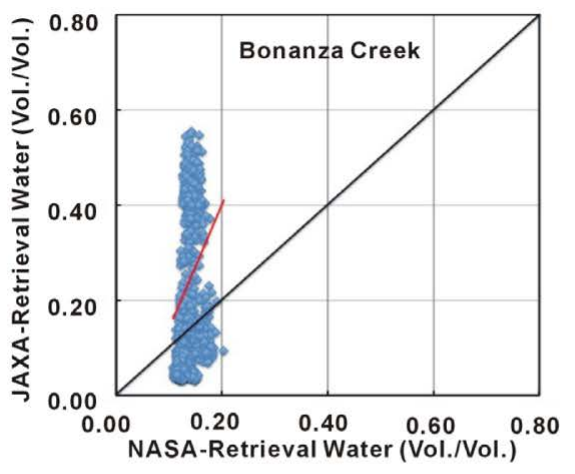

Russia Sites
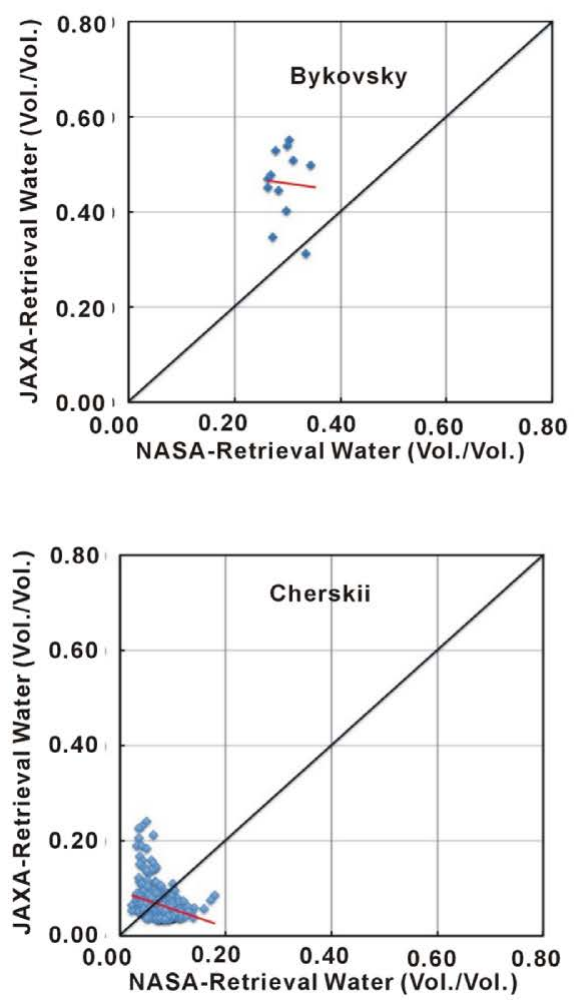
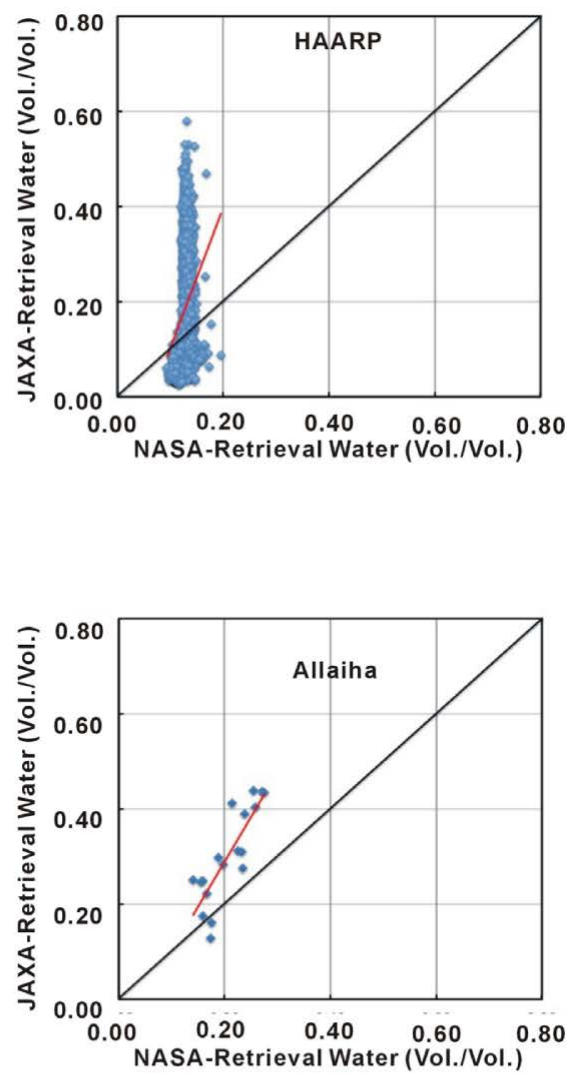

(b)

Figure 7. (a) Colocation-time plots of NASA-algorithm retrievals to JAXA-algorithm retrievals from AMSR-E for sites in Alaska and Russia sites. Time-range for measured soil moisture content is daily (24 hour) average, for retrievals is day-ECT (13:30 local and 01:30 local); (b) Colocation-time plots of NASAalgorithm retrievals to JAXA-algorithm retrievals from AMSR-E for sites in Alaska and Russia sites. Time-range for measured soil moisture content is daily (24 hour) average, for retrievals is day-ECT (13:30 local and 01:30 local).

thaw state change from June 2002 to October 2011 (Figure 4(a), Franklin Bluffs, Happy Valley and Galbraith Lake, respectively). The daily 13:30 and 01:30 ECT time-series show a punctuated cyclical response like the time series from Barrow, although with missing values through winter months. The retrieval soil moisture content varies from minima near 0.1 vol./vol. to maxima near 0.36 vol./vol., on average. At Franklin Bluffs the 


\section{Alaska Sites}
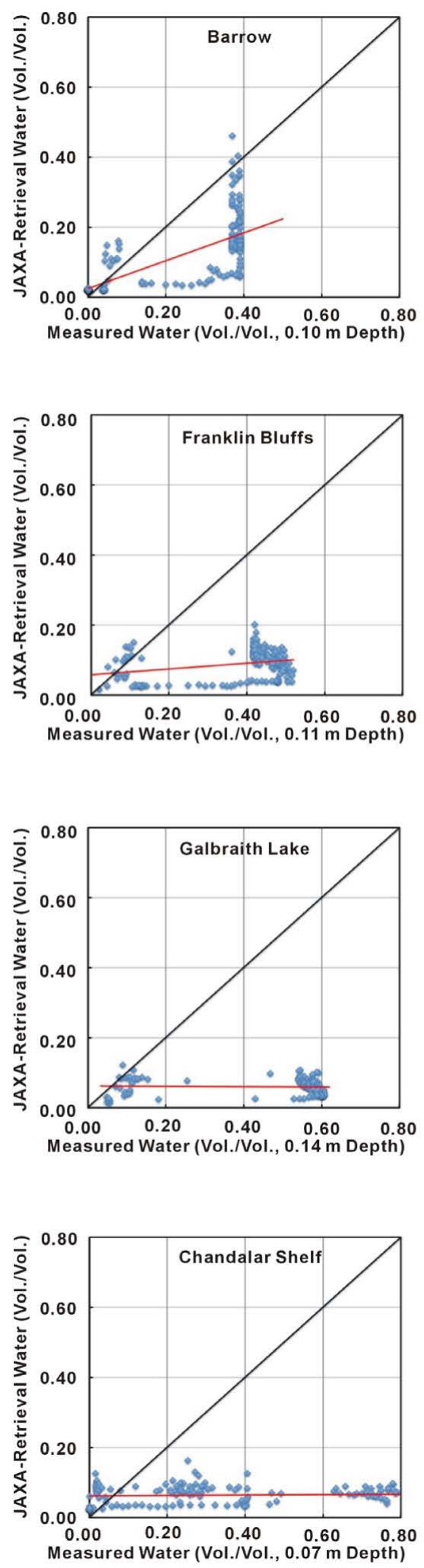
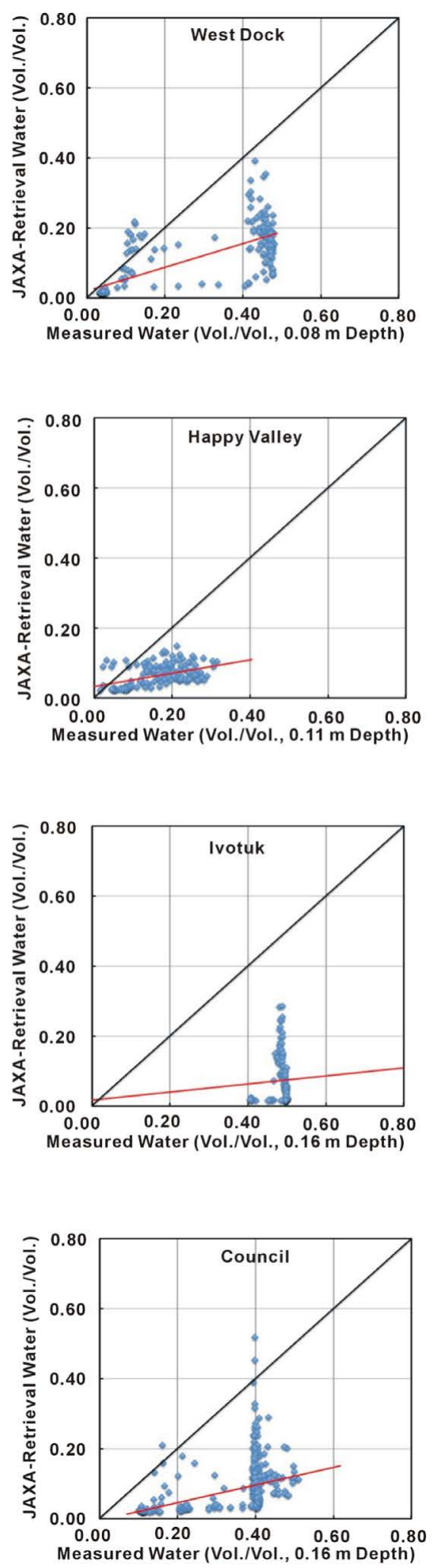

(a) 


\section{Alaska Sites Continued}
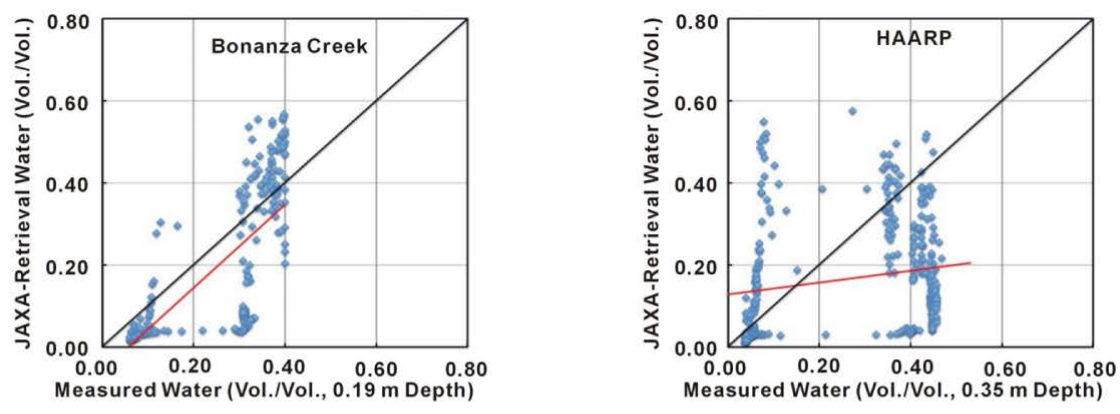

\section{Russia Sites}
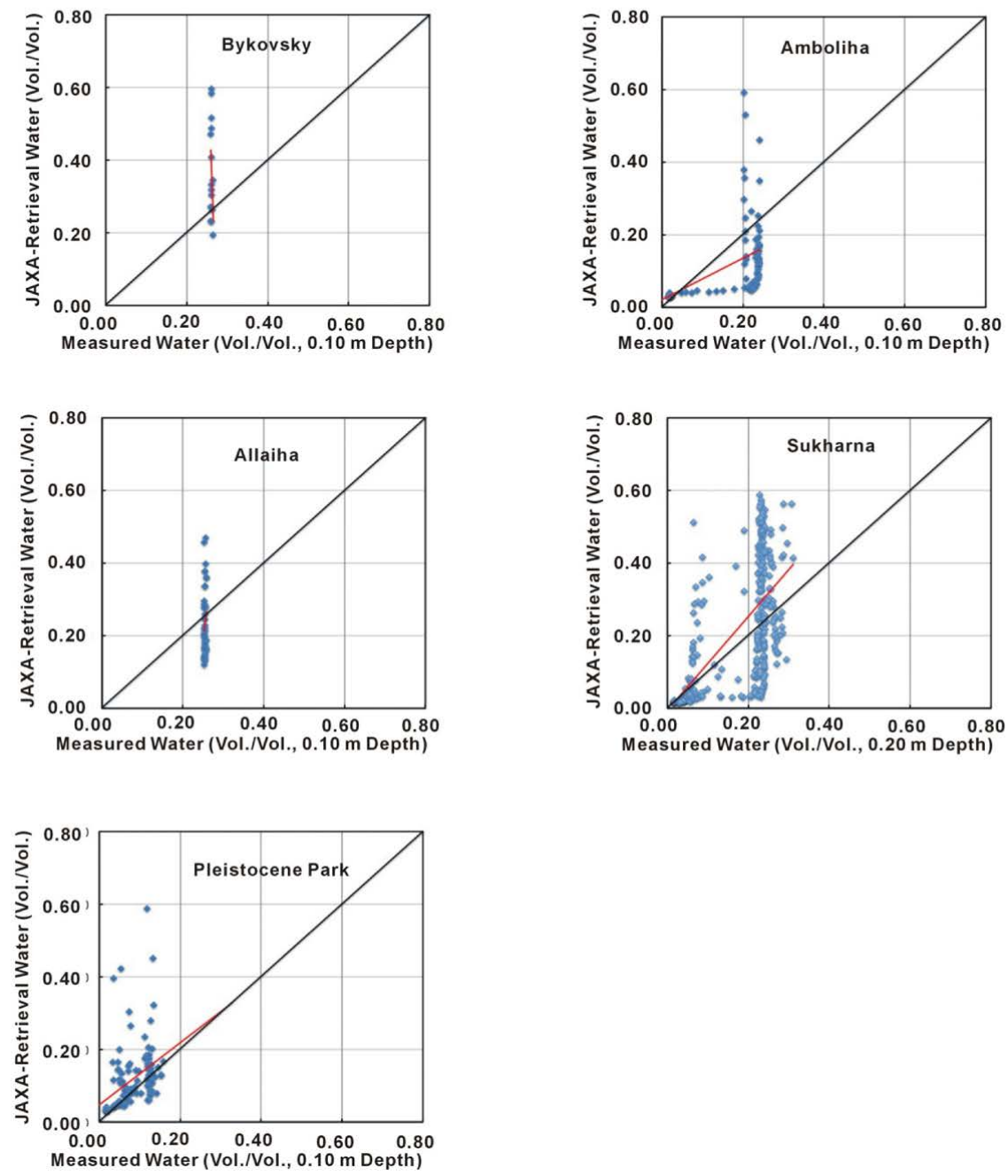

(b)

Figure 8. (a) Colocation-time plots of measured soil moisture content with JAXA-algorithm retrievals from AMSR2 for sites in Alaska Russia sites. Time-range for measured soil moisture content is daily (24 hour) average, for retrievals is day-ECT (13:30 local and 01:30 local); (b) Colocation-time plots of measured soil moisture content with JAXA-algorithm retrievals from AMSR2 for sites in Alaska Russia sites. Time-range for measured soil moisture content is daily ( 24 hour) average, for retrievals is day-ECT (13:30 local and 01:30 local). 


\section{NASA-Algorithm 13:30 ECT}

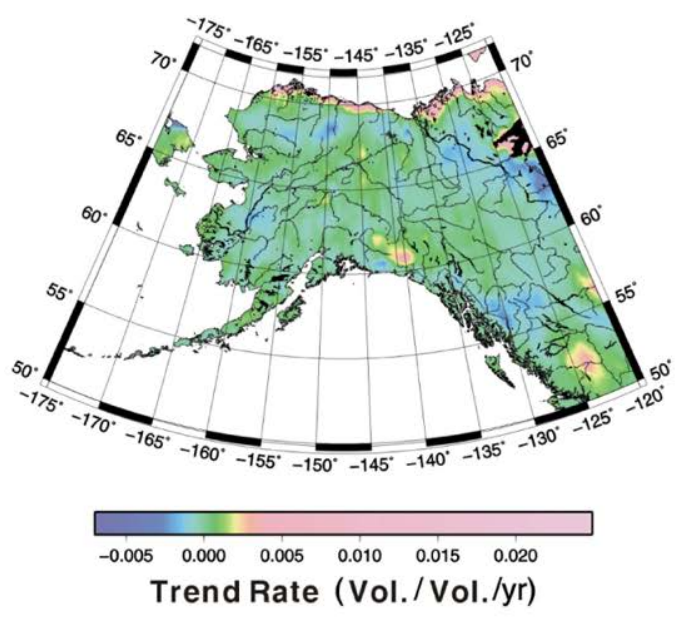

\section{NASA-Algorithm 01:30 ECT}

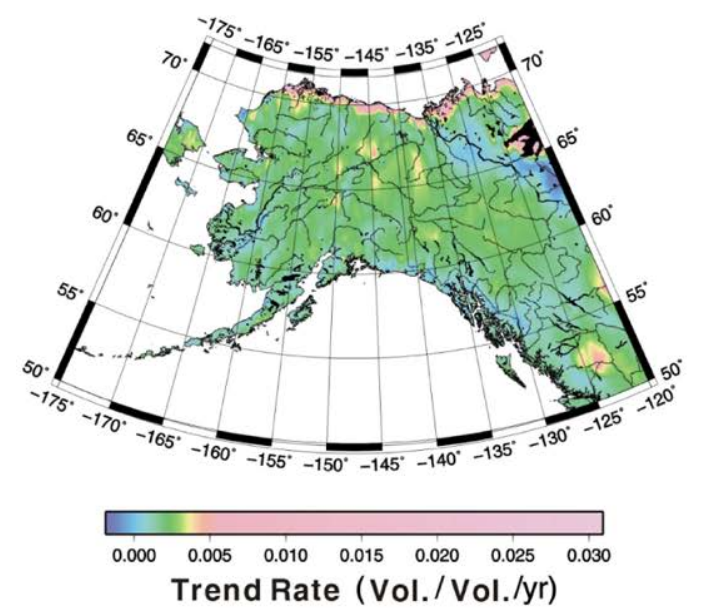

\section{JAXA-Algorithm 13:30 ECT}

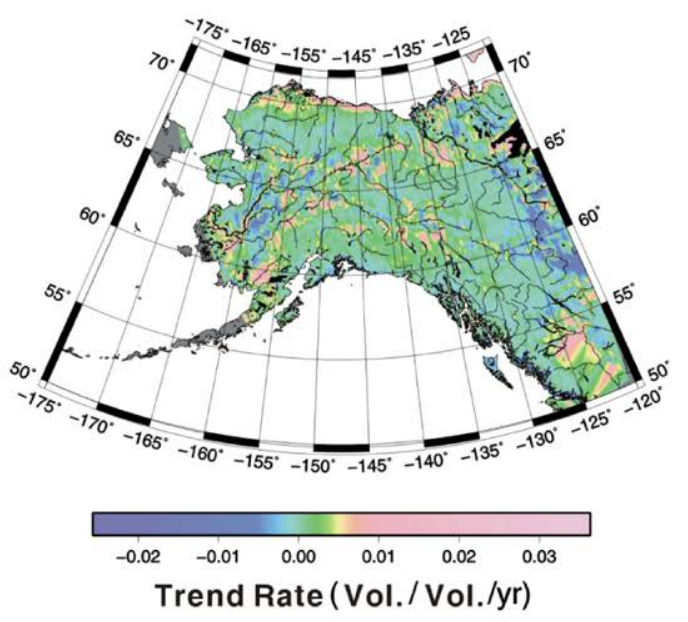

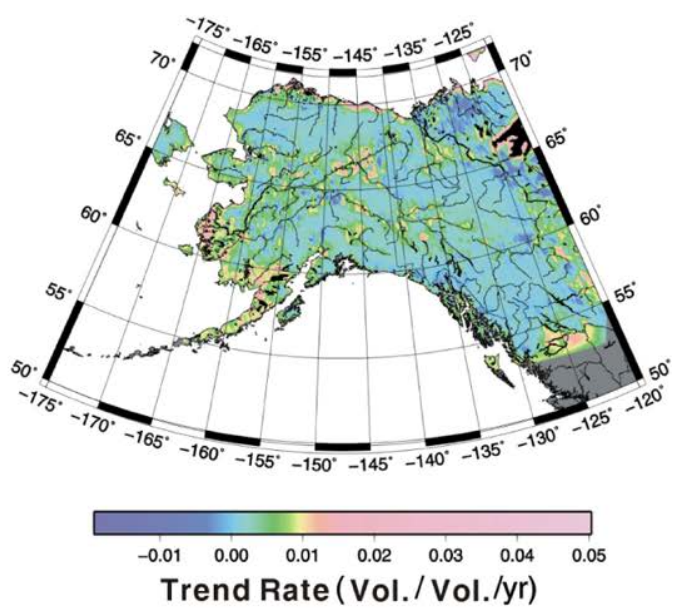

Figure 9. Maps of colocation spatial trends (rates) of AMSR-E NASA- and JAXA-algorithm retrieval soil moisture content at specific Equator Crossing Times on western North America from June 2002 to October 2011.

years 2003-4 and 2009 have bimodal maxima during May and July of those years (Figure 4(a), Franklin Bluffs). At Happy Valley the retrieval maxima soil moisture content display a range from 0.2 to 0.47 vol./vol. with years 2003 and 2009 having a bimodal punctuated response (Figure 4(a), Happy Valley). At Galbraith Lake the cyclical punctuated response of the time-series ranges from 0.1 to 0.43 vol./vol. in years 2002-3 and 2009 with bimodality, to 0.15 to $0.28 \mathrm{vol./vol}$. (single mode) during the other years (Figure 4(a), Galbraith Lake). NASAalgorithm retrieval average soil moisture content is 0.14 (13:30 ECT) and 0.12 vol./vol. (01:30 ECT) with standard deviation of 0.05 and 0.04 vol./vol. at Franklin Bluffs, 0.18 (13:30 ECT) and 0.16 vol./vol. (01:30 ECT) with standard deviation of 0.05 and 0.04 vol./vol. at Happy Valley, 0.18 (13:30 ECT) and 0.17 vol./vol. (01:30 ECT) with standard deviations of 0.03 vol./vol. at Galbraith Lake, respectively. 


\section{NASA-Algorithm 13:30 ECT}
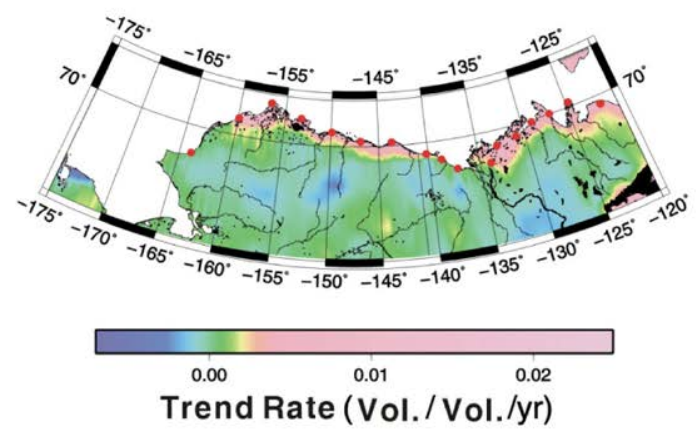

\section{NASA-Algorithm 01:30 ECT}

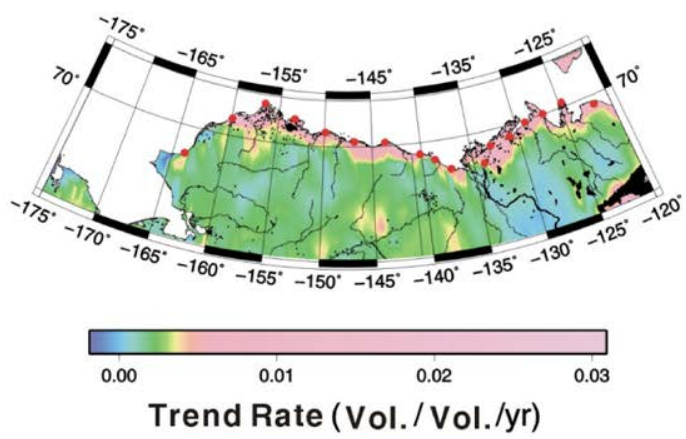

\section{JAXA-Algorithm 13:30 ECT}
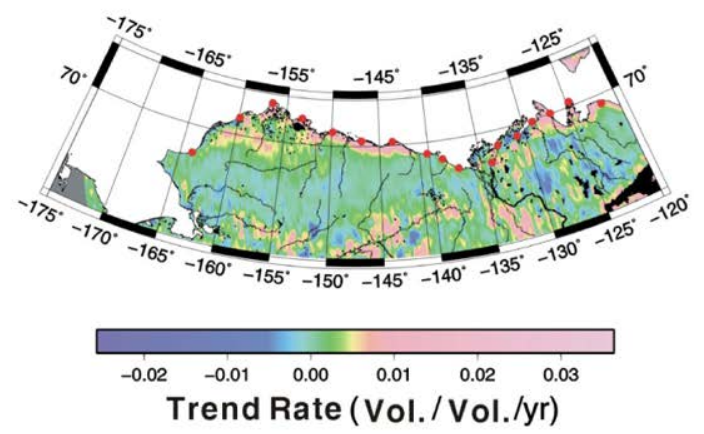

JAXA-Algorithm 01:30 ECT

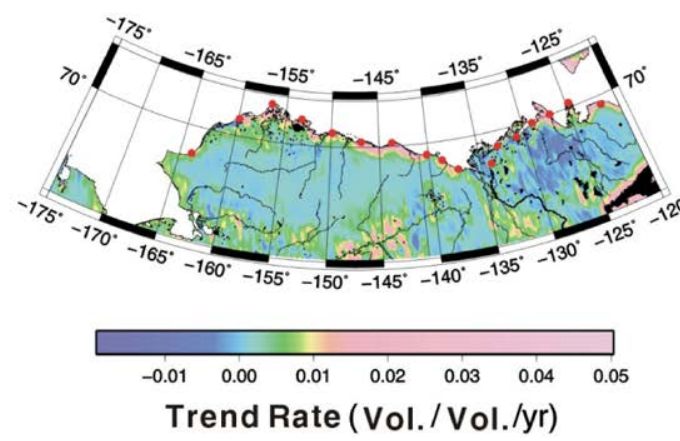

Figure 10. Close-up of the colocation maps of retrieval trends soil moisture content from Figure 9 with plotted locations of civilian and governmental radar and telecommunications, urban areas and gas-oil infrastructure (L, C and $\mathrm{X}$ Band) sites along the north coast of Alaska and western Canada.

Daily AMSR-E JAXA-algorithm retrievals show change of freeze-thaw state that have good correspondence in the early-thaw period in June but lacks correspondence with the early-freeze period August with our VHFprobe measurements on a day-of-month basis (Figure 4(a), Franklin Bluffs, Happy Valley and Galbraith Lake, respectively). The miss-match is most apparent at the Galbraith Lake site on the upper Foothills. JAXA-algorithm retrieval averages are 0.09 (13:30 ECT) and 0.06 vol./vol. (01:30 ECT) vol./vol. with standard deviation of 0.03 and 0.02 vol./vol. with June/July maxima near 0.44 vol./vol. at Franklin Bluffs, decrease to 0.06 (13:30 ECT) and 0.04 vol./vol. (01:30 ECT) with standard deviation of 0.06 and 0.03 vol./vol. with the June/July maxima increase to near 0.57 vol./vol. at Happy Valley then at Galbraith Lakea reduction to 0.05 (13:30 ECT) and increase to $0.29 \mathrm{vol} . / \mathrm{vol}$. (01:30 ECT) with standard deviation 0.03 and $0.01 \mathrm{vol} . / \mathrm{vol}$. and June/July maxima near 0.38 vol./vol. at Franklin Bluffs, 0.57 vol./vol. at Happy Valley and 0.40 vol./vol. at Galbraith Lake, respectively. In many respects the JAXA-algorithm retrieval averages under-perform the NASA-algorithm averages at these sites. The JAXA-algorithm retrieval ranges over-perform the NASA-algorithm retrievals and under-perform our VHF-probe measurement ranges. The daily AMSR2 JAXA-algorithm retrieval soil moisture content display a decrease, on average, relative to those of AMSR-E at the sites and retain values near zero during winter months.

The Arctic Russia sites are within floodplains and lowlands of the Allaiha and Kolyma Rivers (Figure 4(b), Allaiha, and Cherskii, Amboliha and Pleistocene Park, respectively, and Table 4). Ground vegetation consists of 
Table 5. Regression coefficients $\left(\mathrm{R}^{2}\right)$ of co-located soil moisture content algorithm retrievals to ground measurements.

\begin{tabular}{|c|c|c|c|c|}
\hline & AMSR-E JAXA vs Site & AMSR-E NASA vs Site & AMSR-E JAXA vs NASA & AMSR2 JAXA vs Site \\
\hline \multicolumn{5}{|l|}{ Alaska } \\
\hline Barrow & 0.62 & 0.04 & 0.10 & 0.56 \\
\hline West Dock & 0.72 & 0.00 & 0.30 & 0.58 \\
\hline Franklin B. & 0.57 & 0.04 & 0.17 & 0.08 \\
\hline Happy V. & 0.20 & 0.08 & 0.08 & 0.03 \\
\hline Galbraith L. & 0.49 & 0.00 & 0.13 & 0.00 \\
\hline Ivotuk & 0.22 & 0.19 & 0.04 & 0.00 \\
\hline Chandalar S. & 0.54 & 0.10 & 0.12 & 0.01 \\
\hline Council & 0.38 & 0.00 & 0.04 & 0.18 \\
\hline Bonanza C. & 0.56 & 0.00 & 0.06 & 0.56 \\
\hline HAARP & 0.20 & 0.08 & 0.08 & 0.03 \\
\hline \multicolumn{5}{|l|}{ Russia } \\
\hline Bykovsky & 0.19 & 0.49 & 0.00 & 0.16 \\
\hline Allaiha & 0.01 & 0.20 & 0.70 & 0.02 \\
\hline Cherskii & 0.47 & 0.20 & 0.10 & \\
\hline Sukharna & & & & 0.45 \\
\hline Amboliha & & & & 0.19 \\
\hline Pleistocene Park & & & & 0.16 \\
\hline
\end{tabular}

tundra tussock grasses and boreal larch forest, meadow and shrub lands. The active-layer soils can be at times near saturation as in floodplains and well drained in the forest and shrub sites. The site at Pleistocene Park, a research and ecosystem restoration experiment station $5 \mathrm{~km}$ south of Chersky is within the boreal steppe ecosystem of the Kolyma River lowland [48].

At Allaiha (Figure 4(b), Allaiha) site the VHF-probe soil moisture content at $0.10 \mathrm{~m}$ depth has a seasonal range of 0 to $0.26 \mathrm{vol} . / \mathrm{vol}$. with a thaw season average of $0.25 \mathrm{vol} . / \mathrm{vol}$. with a standard deviation of 0.01 vol./vol. The AMSR-E NASA-algorithm retrievals show soil moisture content range of 0.2 to $0.3 \mathrm{vol} . / \mathrm{vol}$. with averages of 0.21 (13:30 ECT) and 0.2 vol./vol. (01:30 ECT) with standard deviations of 0.05 and 0.04 vol./vol., respectively, over the last days of AMSR-E operations from 9 September to 3 October 2011 corresponding with the beginning of the VHF-probe data acquisitions. The AMSR-E JAXA-algorithm retrievals show soil moisture content range of 0.11 to $0.49 \mathrm{vol} . / \mathrm{vol}$. with averages of 0.28 (13:30 ECT) and 0.18 (01:30 ECT) with standard deviations of 0.14 and $0.12 \mathrm{vol} . / \mathrm{vol}$., respectively. The AMSR2 JAXA-algorithm retrievals show soil moisture range of 0.09 to $0.59 \mathrm{vol} . / \mathrm{vol}$. with near identical averages and standard deviations at the respective ECTs.

The Cherskii site (Figure 4(b), Cherskii) is near the settlement of Chersky and the Kolyma River within tundra tussock and floodplain shrub. The VHF-probe soil moisture content at $0.12 \mathrm{~m}$ depth shows a thaw season range of 0 to $0.40 \mathrm{vol} . / \mathrm{vol}$. with thaw season average of 0.40 and standard deviation of $0.01 \mathrm{vol} . / \mathrm{vol}$. during four-years operation form May 2001 to July 2005. During the thaw season the daily reading have bimodal character with early June mode near $0.40 \mathrm{vol}$./vol. followed by a second mode in early July of 0.23 to $0.39 \mathrm{vol} . / \mathrm{vol}$. soil moisture content. The bimodal character may be due to spring flooding and vegetation response in addition to vegetation heterogeneity given the IFOV at this site. The AMSR-E NASA-algorithm shows a thaw season range of 0.1 to 0.2 vol./vol. from July 2002 through August 2005. The thaw season NASA-algorithm retrieval soil moisture content shows averages of 0.06 (13:30 ECT) and 0.08 vol./vol. (01:30 ECT) with standard devia- 
tions of 0.03 vol./vol. over this period. The AMSR-E JAXA-algorithm retrieval soil moisture content shows a thaw season range of 0.02 to $0.40 \mathrm{vol} . / \mathrm{vol}$. with of average 0.08 and standard deviation of 0.05 vol./vol. at both ECTs.

The Amboliha site (Figure 4(b), Amboliha) is within a sector of the Kolyma River floodplain where thaw lakes are present. The VHF-probe at $0.10 \mathrm{~m}$ depth shows a thaw season soil moisture content range of 0 to 0.24 vol./vol. and thaw season average of 0.24 with standard deviation of $0.01 \mathrm{vol} . / \mathrm{vol}$. for one season of data during summer 2013 to the early May 2014. AMSR2 JAXA-algorithm retrievals show the 2013 season soil moisture content range of 0.02 to 0.59 vol./vol. with averages of 0.20 (13:30 ECT) and 0.23 (01:30 ECT) and standard deviations of 0.12 and 0.16 vol./vol., respectively. We note that the AMSR2 JAXA-algorithm retrievals freezeup timing, i.e. when the retrieval soil moisture decreases to near zero occurs almost two weeks earlier than that shown by the VHF-probe soil moisture content readings. This indicates a miss-match in the vegetation indices adapted from the MODIS 16-day NDVI product used by the JAXA-algorithm.

The Pleistocene Park site (Figure 4(b), Pleistocene Park) is within the Kolyma River floodplain south of Amboliha. The VHF-probe soil moisture content at $0.10 \mathrm{~m}$ depth shows a thaw season range of 0 to 0.43 vol./vol. from July 2013 through July 2014. AMSR2 JAXA-algorithm retrieval soil moisture content shows a thaw season range of 0.02 to $0.60 \mathrm{vol} . / \mathrm{vol}$., with thaw season averages of 0.18 (13:30 ECT) and 0.16 (01:30 ECT) vol./vol. with standard deviations of 0.11 vol./vol., respectively, over the two-year period.

Co-location and co-time comparisons Figure 5(a) (Franklin Bluffs, Happy Valley and Galbraith Lake) and Figure 5(b) (Allaiha, Cherskii, Amboliha, and Pleistocene Park) and Table 5 show the AMSR-E JAXA-algorithm retrieval versus measurement site $\mathrm{R}^{2}$ with the highest values, modest significance, at Franklin Bluffs, Galbraith Lake and Cherskii. Happy Valley and Allaiha have low $\mathrm{R}^{2}$ values that are not significant. The AMSR-E NASA-algorithm retrieval versus measurement site $\mathrm{R}^{2}$ shows very low values and no significance (Figure 6(a) and Figure 6(b) and Table 5). At Alliaha site both the AMSR-E JAXA and NASA-retrieval versus measurement $\mathrm{R}^{2}$ scores indicate no correlation. This scoring by $\mathrm{R}^{2}$ does indicate that the AMSR-E JAXA-algorithm is significantly different relative to the AMSR-E NASA-algorithm (Figure 7(a) and Figure 7(b) and Table 5). The AMSR2 JAXA-algorithm retrievals versus measurement site $\mathrm{R}^{2}$ scores at Franklin Bluffs, Happy Valley, Galbraith Lake, Alliaha and Cherskii (Figure 7(a) and Figure 7(b) and Table 5) indicate no correlation.

\subsection{Ivotuk and Chandalar Shelf Site: Upper Foothills and Brooks Range, Alaska}

The Ivotuk and Chandalar Shelf sites (Figure 4(a), Ivotuk and Chandalar, Table 4), continuous permafrost zoneexhibit similar upland tundra vegetation cover with contrasting setting; one on a north-facing broad-flat upland flanking north on the Brooks Range and the other in a south-facing central broad-flat upland valley within the Brooks Range south of Atigun Pass. These sites show the highest VHF-probe measured soil moisture content. Thaw is rapid in late-May at Ivotuk with the June/July bimodal maxima near 0.88 vol./vol. at $0.16 \mathrm{~m}$ depth and a sharp drop in the last year of data, 2013 to near 0.5 without the bimodal character. After the rapid late-May thaw at Chandalar Shelf the June/July soil moisture content maxima reach near 0.96 vol./vol. at $0.07 \mathrm{~m}$ depth with a variation over the years from near 0.96 vol./vol. in 2002 to 0.78 vol./vol. in 2013. Over the data period at Chandalar Shelf the maxima display both a bimodal and a single modal character in VHF-probe soil moisture content measurements.

The daily AMSR-E NASA-algorithm retrievals at the Ivotuk and Chandalar Shelf sites (Figure 4(a), Ivotuk and Chandalar, Table 4) show a small range cyclical variation of soil moisture content during the short summers from June 2002 to October 2011 that does not correspond to the VHF-probe soil moisture content variation. Retrieval values during winter months are missing and summer variation of soil moisture content range from 0.2 to 0.47 vol./vol. at Ivotuk and and 0.1 to 0.34 vol./vol. at Chandler Shelf. NASA-algorithm retrieval average soil moisture content is 0.16 (13:30 ECT) and 0.16 vol./vol. (01:30 ECT) with standard deviations of 0.04 vol./vol. at Ivotuk and 0.15 (13:30 ECT) and 0.16vol./vol. (01:30 ECT) with standard deviations of 0.02vol./vol. at Chandalar Shelf. Daily AMSR-E JAXA-algorithm retrieval average soil moisture content is 0.08 (13:30 ECT) and 0.05 vol./vol. (01:30 ECT) with standard deviation 0.09 and 0.05 vol./vol. at the Ivotuk and 0.05 (13:30 ECT) and 0.04 vol./vol. (01:30 ECT) with standard deviation 0.03 and 0.02 vol./vol. at the Chandalar Shelf. At the Chandalar Shelf the NASA-algorithm retrieval soil moisture over-perform the JAXA-algorithm retrieval soil moisture by about 0.1 vol./vol. yet both algorithm retrieval soil moisture substantially under-perform relative the VHF-probe soil moisture content measurements. The AMSR2 JAXA-algorithm retrieval soil moisture content 
for years 2012 and 2013 show a slight, on-average increase relative to those of AMSR-E.

The JAXA-algorithm retrievals show freeze-thaw state changes such that the early-thaw period has relatively good correspondence with the VHF-probe measurements on a day-of-month basis but the early-freeze period has poor correspondence with the VHF-probes at both sites (Figure 4(a) and Table 4). NASA-algorithm retrieval seasonal maxima are up to $0.47 \mathrm{vol} . / \mathrm{vol}$. whereas the JAXA-algorithm retrieval seasonal maxima are near 0.59 vol./vol. over the period from June 2002 to October 2011. At Ivotuk June 2009 shows the upper limit of the maxima for both algorithms retrieval soil moisture content at their ECTs, 0.47 and 0.4 vol./vol. (13:30 and 01:30) NASA and 0.59 and 0.54 vol./vol. (13:30 and 01:30) JAXA. This particular feature of the retrievals does not correspond to VHF-probe soil moisture content measurements. The daily AMSR2 JAXA-algorithm retrievals from July 2012 trough December 2013 continue the AMSR-E JAXA-algorithm retrieval soil moisture content values and seasonal character.

Co-location and co-time comparisons Figure 5(a) (Ivotuk and Chandalar) and Table 5 show the AMSR-E JAXA-algorithm retrieval versus measurement site $\mathrm{R}^{2}$ with the highest value and modest significance at the Chandalar site. The AMSR-E JAXA-algorithm retrieval versus measurement at Ivotuk shows low $\mathrm{R}^{2}$ that is not significant (Figure 5(a) and Table 5). The AMSR-E NASA-algorithm retrieval versus measurement site $\mathrm{R}^{2}$ show low values and no significance at both Ivotuk and Chandalar sites (Figure 6(a) and Table 5). The AMSR2 JAXA-algorithm retrievals versus measurement site $\mathrm{R}^{2}$ scores have the lowest values and no significance (Figure 8(a) and Table 5).

\subsection{Council Site, Seward Peninsula, Alaska}

The Council site on the Seward Peninsula is located about 6 km northwest of Council (town) on a low-to-moderate reliefdense hardwood shrub, about $1.5 \mathrm{~m}$ height, dominated tussock tundra terrain. The site location is within the discontinuous permafrost zone. Winter VHF-probe soil moisture content measurement at $0.16 \mathrm{~m}$ depth has values near 0.08 vol./vol. and temperature as low as $-1.3^{\circ} \mathrm{C}$. The Seward Peninsula is well known for its geothermal hot springs, Quaternary basalt flows and the Pleistocene hydromagmatic Espenberg Maars [49]. VHP-probe soil moisture content measurement show the early-thaw soil moisture rapidly rising to maxima of 0.56 to $0.62 \mathrm{vol} . / \mathrm{vol}$. then arapid drop to values near $0.4 \mathrm{vol} . / \mathrm{vol}$. that persists into November, likely a vegetation response and followed by another rapid drop in the values as the active-layer re-freezes (Figure 4(a) and Table 4). Our VHF-probe soil moisture content measurements span 2002 through 2010, due to access difficulty. To compare with the AMSR2 retrievals we compose Julian-day averages from the preceding series.

At Council site the daily AMSR-E NASA-algorithm retrievals show a cyclical response during thaw-months from near 0.11 to near $0.27 \mathrm{vol} . / \mathrm{vol}$. (13:30 ECT) and from as low as 0.03 to near 0.22 vol./vol. (01:30 ECT) with a maxima of 0.38 (13:30 ECT, May 2010) and 0.3 vol./vol. (01:30 ECT, April 2009) over the period from June 2002 to October 2011 (Figure 4(a) and Table 4). NASA-algorithm retrieval average soil moisture content is 0.14 (13:30 ECT) and 0.14 vol./vol. (01:30 ECT) with standard deviation 0.03 and $0.02 \mathrm{vol} . / \mathrm{vol}$. at this upland shrub-tussock site. The daily AMSR-E JAXA-algorithm retrievals show a soil moisture content show seasonal thaw response very similar to the VHF-probe measurements from a low near 0.02 up to near $0.56 \mathrm{vol} . / \mathrm{vol}$. (13:30 ECT) and from a low near 0.03 to up to near 0.5 vol./vol. (01:30 ECT). JAXA-algorithm retrieval average soil moisture content is 0.11 (13:30 ECT) and 0.09 vol./vol. (01:30 ECT) with standard deviation 0.12 and 0.1 vol./vol. over the period. While the thaw timing shown in the JAXA-algorithm retrievals have good correspondence with the VHF-probe measurements the timing of the freeze appears aliased, by turning the retrieval seasonal response into a spike-like function. Thus the JAXA-algorithm retrieval freeze response occurs during Augusts whereas the VHF-probe measurement response occurs during Novembers. The AMSR2 JAXA-algorithm retrieval soil moisture content has very similar seasonal response and value magnitudes as those of the AMSR-E JAXA-algorithm retrievals at this site.

Co-location and co-time comparisons Figure 5(a) (Council) and Table 5 show the AMSR-E JAXA-algorithm retrieval versus measurement site $\mathrm{R}^{2}$ with a value and low significance. The AMSR-E NASA-algorithm retrieval versus measurement site $\mathrm{R}^{2}$ shows no correlation (Figure 6(a) and Table 5). The AMSR2 JAXA-algorithm retrievals versus measurement site $\mathrm{R}^{2}$ score lower relative to the AMSR-E JAXA score (Figure 8(a) and Table 5).

\subsection{Bonanza Creek LTER Site Tanana Flats, Central Alaska}

Southwest of the University of Alaska Fairbanks in the Tanana Flats River region of the Yukon River watershed 
is the Bonanza Creek Long-Term Ecological Research (LTER) site ${ }^{3}$. Our permafrost-monitoring site in the discontinuous permafrost zone is within an upland Spruce forest with moderate topographic relief and gullies on the north flank of the Tanana River and experienced wildfire burning in 1983. Thaw occurs rapidly over a few day in early May and freeze occurs rapidly over a few days in late September. 2004 was noteworthy for the early thaw in April and late freeze extending into November. VHF-probe soil moisture content measurement reach maxima of $0.40 \mathrm{vol} . / \mathrm{vol}$. at $0.19 \mathrm{~m}$ depth in June and some years have a reduction occur over July and August before the rapid freeze. Outages occurred in 2004 through 2005 and 2007 into October 2009 (Figure 4(b) and Table 4).

The daily AMSR-E NASA-algorithm retrievals show a soil moisture content cyclical response of 0.11 to 0.22 vol./vol. (13:30 ECT) and 0.16 to 0.17 vol./vol. (01:30 ECT) over the period from June 2002 to October 2011. Retrieval values during winter days are missing (Fig. $4 \mathrm{~b}$ and Table 4). NASA-algorithm retrieval average soil moisture content is 0.14 (13:30 ECT) and 0.14 vol./vol. (01:30 ECT) with standard deviation 0.02 vol./vol. and $0.01 \mathrm{vol} . / \mathrm{vol}$., respectively, at this boreal forest site. NASA-algorithm retrieval maxima soil moisture content is 0.23 (13:30 ECT) and 0.29 vol./vol. (01:30 ECT), 0.26 vol./vol., on average. The daily AMSR-E JAXA-algorithm retrievals show a soil moisture content seasonal response during thaw of 0.03 to 0.58 vol./vol. (13:30 ECT) and 0.03 to 0.59 vol./vol. (01:30 ECT). JAXA-algorithm retrieval average soil moisture content is 0.17 (13:30 ECT) and 0.16 vol./vol. (01:30 ECT) with standard deviation 0.16 and 0.18 vol./vol., respectively. The rapid early thaw corresponds well with the timing of thaw by the VHF-probe measurements with a relative over-performance of maxima by about $0.20 \mathrm{vol} . / \mathrm{vol}$. over the period. The JAXA-algorithm retrieval timing of the early freeze occurs about 15 days ahead of the early freeze timing as measured by the VHF-probe measurements. The AMSR2 JAXA-algorithm retrieval soil moisture content has very similar characters and thaw-freeze responses as those of the AMSR-E retrievals at this site.

Co-location and co-time comparisons Figure 5(b) (Council) and Table 5 show the AMSR-E JAXA-algorithm retrieval versus measurement site $\mathrm{R}^{2}$ a high value of modest significance. The AMSR-E NASA-algorithm retrieval versus measurement site $\mathrm{R}^{2}$ shows no correlation. The AMSR2 JAXA-algorithm retrievals versus measurement site $\mathrm{R}^{2}$ score is the same as AMSR-E JAXA, and of modest significance.

\subsection{Site at the HAARP Facility, South-Central Alaska}

Our permafrost-monitoring site in the discontinuous-sporadic permafrost zone of south-central Alaska is at the High-Frequency Active Auroral Research Program (HAARP) site (Figure 4(b) and Table 4). On the east side of the HAARP facility our permafrost-monitoring site is within the spruce-hardwood forest with understory vegetation of willow and alder with litter-covered ground of lichen and moss. Our shallowest VHF-probe is at $0.35 \mathrm{~m}$ depth to avoid shallow roots and the surface organic mat. Winter VFH-probe soil moisture content measurements show a range from 0 to $0.1 \mathrm{vol} . / \mathrm{vol}$. and typical minima from 0.01 to $0.04 \mathrm{vol} . / \mathrm{vol}$. over the period from August 2004 to October 2011. Thaw response begins in mid-March and soil moisture content rapidly increases in value to maxima near 0.47 and as high as 0.53 vol./vol. with a quick reduction to a level near 0.41 to 0.45 vol./vol. that persists from July to September. This response is similar to our measurements at the Council site and likely a vegetation response imprinted on the soil moisture content.

The daily AMSR-E NASA-algorithm retrievals show a soil moisture content cyclical response, similar to the Council site, of 0.13 to 0.26 vol./vol. (13:30 ECT) and 0.12 to 0.15 vol./vol. (01:30 ECT) over the period from June 2002 to October 2011 (Figure 4(b) and Table 4). NASA-algorithm retrieval average soil moisture content is 0.13 (13:30 ECT and 01:30 ECT) with standard deviation 0.02 and $0.01 \mathrm{vol} . / \mathrm{vol}$. at this forest site. NASAalgorithm retrieval maxima soil moisture content is 0.26 (13:30 ECT) and 0.21 vol./vol. (01:30 ECT). The daily AMSR-E JAXA-algorithm retrievals show a soil moisture content seasonal response during thaw, similar to the Council site, of 0.03 to $0.56 \mathrm{vol} . / \mathrm{vol}$. (13:30 ECT) with four of the maxima near $0.6 \mathrm{vol} . / \mathrm{vol}$., and 0.03 to 0.57 vol./vol. (01:30 ECT) over the period. JAXA-algorithm retrieval average soil moisture content is 0.12 (13:30 ECT) and 0.11 vol./vol. (01:30 ECT) with standard deviation 0.11 and 0.13 vol./vol. over the period. The rapid early-thaw corresponds well with the timing of thaw by the VHF-probe measurements with a relative over-performance of maxima as much as $0.20 \mathrm{vol}$./vol. relative to the VHF-probe measurements over the period. The JAXA-algorithm retrieval timing of the freeze response is similar to that found at Council site and occurs about 60 days ahead of the early freeze timing as measured by the VHF-probe measurements. The AMSR2 JAXA-

\footnotetext{
${ }^{3}$ http://www.lter.uaf.edu/about us.cfm.
} 
algorithm retrieval soil moisture content has very similar characters and thaw-freeze responses as those of the AMSR-E retrievals at this site.

Co-location and co-time comparisons Figure 5(b) (HAARP) and Table 5 show the AMSR-E JAXA-algorithm retrieval versus measurement site $\mathrm{R}^{2}$ with a low value and no significance. The AMSR-E NASA-algorithm retrieval versus measurement site $\mathrm{R}^{2}$ has no correlation (Figure 6(b) and Table 5). The AMSR2 JAXA-algorithm retrieval versus measurement site $\mathrm{R}^{2}$ score has the lowest value and no significance (Figure 8(b) and Table 5).

\subsection{Trends of Soil Moisture Content}

Least-squares Analysis of Variance of all the time-series indicates no significant trends in soil moisture content by algorithmic retrieval or ground measurement on a site-by-site basis. In addition there are no significant correlations of soil moisture content by algorithmic retrieval to ground measurement on a site-by-site basis. The ground measurements display a latitudinal variation in their maxima of soil moisture content with the lowmaxima values at stations near the northern coasts of the Arctic Ocean and the high-maxima values at stations near the Brooks Range in Alaska. This is likely an effect of topography. The NASA-algorithm retrievals do not display seasonality, i.e. a change of the freeze/thaw state. Also the NASA-algorithm retrievals under-perform, i.e. are less than, relative to ground measurements at all stations in Alaska and Russia. The JAXA-algorithm retrievals by comparison do show seasonality, which does correspond to the seasonality displayed by the ground measurements. The JAXA-algorithm retrievals do have late-season issues in performance at interior Alaska boreal forest sites relative to ground measurements, and this is likely a vegetation parameter artifact of the retrieval algorithm. The JAXA-algorithm retrievals do over-perform, i.e. are greater than, ground measurements at sites in Alaska and Russia with tundra vegetation, likely a vegetation parameter artifact of the retrieval algorithm an under-perform elsewhere, in part, likely an effect of topography, mixed-vegetation types and the IFOV per channel of the AMSR-E and AMSR2 sensors.

\section{Assessment of Microwave Sensing Soil Moisture Content}

\subsection{Trends per Site}

NASA-algorithm for soil moisture content by AMSR-E under-performs, i.e. the retrieval value is less than the ground-measured value, at all locations in Alaska and Russia, Figure 4 through Figure 8. The under-performance is likely a function of $T_{B_{10,65}}^{\text {OBS }}$, assumed $T_{s}$ and vegetation parameters from look-up table values which do not correspond to actual environment conditions. The non-seasonality (freeze/thaw and vegetation response) of the NASA-algorithm and mismatch with ground measurements is evident. Missing daily retrieval soil moisture content values during winter is likely due to an arbitrary land-mask that presumes a frozen state but does not correspond to actual environmental condition. JAXA-algorithm for soil moisture content by AMSR-E and AMSR2 show improvement in performance at all locations in Alaska and Russia relative to ground-measurements yet over-performance at tundra sites is evident. This is likely due to incorporation of MODIS $T_{s}$ as a proxy for skin temperature and MODIS NDVI vegetation parameters, which have a closer correspondence to actual environmental conditions. Use of MODIS derived parameters restores seasonality into the soil moisture content. At boreal forest sites in Alaska the JAXA-algorithm retrievals have performance issue with late-season vegetation from MODIS NDVI 16-day composite and this produces a drop-off in retrieval soil moisture content that does not correspond to ground measurements. For the northern high latitudes the MODIS NDVI 16-day composite produces aliased timing of brown-up, which is likely a miss-match presumed vegetation type from ancillary data used in the processing. An additional influence of the late-season as well as early-season missmatch derives from yearly variations in the snow cover whose microwave emissions can mask those of skin temperature, ground vegetation and soil water content [38].

The performance of the JAXA-algorithm retrievals shows landscape-scale heterogeneity of the microwave channels IFOV (10 s of kilometers sensing-scale) versus the VHF-probeground measurements (centimeter level sensing-scale). This heterogeneity is relatively less for coastal sites nearest the Arctic Ocean in Alaska and Russia (Figure 4(a), Barrow and West Dock and Figure 4(b), Bykovsky, Cherskii and Sukharna) and increases to the south in Alaska where micrometeorology, topography and vegetation types are more varied and mixed relatively to the microwave IFOV.

The period of comparison for the AMSR-E NASA and JAXA-derived algorithm retrievals is from June 2002 
to October 2011. At our Alaska and Russia sites there are no significant trends of soil moisture content. There are significant variations of soil moisture content that derive from environmental setting, particularly orographic effects north-to-south across the Brooks Range and soil composition.

\subsection{Spatial Trends in NASA- and JAXA-Algorithm Retrievals of Soil Moisture Content}

Both NASA- and JAXA-algorithm derived soil moisture content shows spatially co-located and significant emergent trends for daytime and nighttime retrievals, Figure 9 and Figure 10. The trends we find have spatial correspondence to locations of civilian and governmental radar facilities and telecommunications infrastructures and population areas and oil-gas exploration activity particularly evident along the Alaska north coast. It is apparent that since launch in 2002 there has been an increase in terrestrial telecommunications infrastructure using $10.65 \mathrm{GHz}$ as well as other microwave-frequencies in Alaska.

It has been recognized that shortly after the start of operations of the AMSR-E mission on NASA-Aqua contamination by terrestrial radio-frequency interference at $6.925 \mathrm{GHz}$ (C-Band), which necessitated the use of the $10.65 \mathrm{GHz}$ (X-Band) for the primary $T_{B_{10.65}}^{\text {OBS }}$ and soil moisture retrieval [26]. After 2-years of operation significant contamination was apparent in the $10.65 \mathrm{GHz}$ channel though mostly at that time confined to parts of the British Isles, Netherlands, Italy, Southeast Asia and Japan [27] [29].

Our results show spatial trends of nighttime-retrievals have greater magnitude than those of daytime-retrievals, Figure 10. While the sun is a weak source of radiation at $10.65 \mathrm{GHz}$ the galaxy is active at $10.65 \mathrm{GHz}$ [50] [51]. Therefore the nighttime increase in "soil moisture content" based on $T_{B_{1065}}^{\text {OBS }}$ is likely an expression of galactic radio-frequency interference reflected by the land surface and received by the X-Band feed-horn of AMSR-E and AMSR2. Our investigation of the algorithm retrievals through summer 2014 shows continuity in characteristics of the AMSR-E (re-processed) at all of our sites in Alaska and Russia. Further investigation of AMSR2 retrievals for analysis of radio frequency interference is needed.

Future development microwave retrieval algorithms for near-surface soil moisture content and other important environmental parameters need to be aware of the growing effects of radio-frequency interference. As urbanization effects, e.g. the urban heat island effect contaminates near-surface temperature records, radio-frequency interference from man-made and galactic-sources is a form of contamination affecting active and passive microwave receivers and their retrieval products.

\section{Conclusion}

Research efforts into the theory and applications of passive microwave remote sensing of soil moisture on a global scale have been on-going for more than 30 years. Challenges remain in regards to removing the confounding effects of vegetation, vegetation roughness and tropospheric relief effects on surface brightness temperature, skin temperature and emissivity, geophysical parameter retrieval and the source depth of radiation at 6.925 and $10.65 \mathrm{GHz}$ channels currently used in sensors such as AMSR2. At these frequencies, particularly the $10.65 \mathrm{GHz}$ channel there is a growing contamination from radio-frequency interference, an artifact of telecommunication urbanization in the Arctic, in addition to nighttime-retrieval galactic radio-frequency interference in the retrieval soil moisture contents. Progress in sensor design and orbital selection and passive microwave theory are needed to overcome the current challenges.

\section{Acknowledgements}

This research was funded by NSF OPP grants ARC-0856864, and -1304271, and by DOE NGEE grant. The Next-Generation Ecosystem Experiments (NGEE Arctic) project is supported by the Office of Biological and Environmental Research in the DOE Office of Science. We thank NASA, NSIDC and JAXA for providing the AMSR-E and AMSR2 retrieval algorithm soil moisture content datasets. The University of Alaska Geophysical Institute Arctic Region Supercomputing Center is thanked for software such as ENVI/IDL and computing facilities used in this work. The Generic Mapping Tools was used in this research.

\section{References}

[1] Hillel, D. (1980) Fundamentals of Soil Physics. Academic Press, New York.

[2] Delworth, T. and Manabe, S. (1988) The Influence of Potential Evaporation on the Variability of Simulated Soil Wet- 
ness and Climate. Journal of Climate, 13, 2900-2922.

[3] Chang, J.T. and Wetzel, P.J. (1991) Effects of Spatial Variations of Soil Moisture and Vegetation on the Evolution of a Prestorm Environment: A Numerical Case Study. Monthly Weather Review, 119, 1368-1390. http://dx.doi.org/10.1175/1520-0493(1991)119<1368:EOSVOS>2.0.CO;2

[4] Raich, J.W. and Schlesinger, W.H. (1992) The Global Carbon Dioxide Flux in Soil Respiration and Its Relationship to Vegetation and Climate. Tellus B, 44, 81-99. http://dx.doi.org/10.1034/j.1600-0889.1992.t01-1-00001.x

[5] Schar, C., Luthi, D., Beyerle, U. and Heise, E. (1999) The Soil-Precipitation Feedback: A Process Study with a Regional Climate Model. Journal of Climate, 12, 722-741. http://dx.doi.org/10.1175/1520-0442(1999)012<0722:TSPFAP $>2.0 . C O ; 2$

[6] Jackson, R.D. (1973) Diurnal Soil-Water Content Changes during Drying, Field Solar Water Regime. Soil Science Society of America, 5, 37-56.

[7] Blanchard, B.J. and Chang, A.T.C. (1983) Estimation of Soil Moisture from SEASAT SAR Data. Journal of the American Water Resources Association, 19, 803-810. http://dx.doi.org/10.1111/j.1752-1688.1983.tb02803.x

[8] Njoku, E.G. and Kong, J-A. (1977) Theory for Passive Microwave Remote Sensing of Near-Surface Soil Moisture. Journal of Geophysical Research, 80, 3108-3118. http://dx.doi.org/10.1029/JB082i020p03108

[9] Choudhury, B.J. and Golus, R.E. (1988) Estimating Soil Wetness Using Satellite Data. International Journal Remote Sensing, 9, 1251-1257. http://dx.doi.org/10.1080/01431168808954932

[10] Wen, J., Jackson, T.J., Bindlish, R., Hsu, A.Y. and Su, Z.B. (2005) Retrieval of Soil Moisture and Vegetation Water Content Using SSM/I Data over a Corn and Soybean Region. Journal of Hydrometeorology, 6, 854-863. http://dx.doi.org/10.1175/JHM462.1

[11] Gao, H., Wood, E.F., Jackson, T.J., Drusch, M. and Bindlish, R. (2006) Using TRMM/TMI to Retrieve Surface Soil Moisture over the Southern United States from 1998 to 2002. Journal of Hydrometeorology, 7, 23-38. http://dx.doi.org/10.1175/JHM473.1

[12] http://www.remss.com/missions/amsre

[13] http://sharaku.eorc.jaxa.jp/AMSR/ov_amsr/sensor.html

[14] http://suzaku.eorc.jaxa.jp/GCOM/index.html

[15] http://sharaku.eorc.jaxa.jp/AMSR/doc/alg/14_alg.pdf

[16] http://eospso.gsfc.nasa.gov/eos_homepage/for_scientists/atbd/docs/AMSR/atbd-amsr-land.pdf

[17] Poe, G., St Germain, K., Bobak, J., et al. (2001) DMSP Calibration/Validation Plan for the Special Sensor Microwave Imager Sounder (SSMIS). Naval Research Laboratory, Washington DC.

[18] Njoku, E. (2004) AMSR-E/Aqua Daily L3 Surface Soil Moisture, Interpretive Parameters and QC EASE-Grids, March to June 2004. National Snow and Ice Data Center, Digital Media, Boulder.

[19] http://atrain.nasa.gov

[20] http://global.jaxa.jp/press/2011/10/20111004_amsr-e_e.html

[21] http://sharaku.eorc.jaxa.jp/AMSR/products/amsre_slowdata.html

[22] http://suzaku.eorc.jaxa.jp/GCOM_W/data/doc/NDX-120015A.pdf

[23] Njoku, E.G. and Li, L. (1999) Retrieval of Land Surface Parameters Using Passive Microwave Measurements at 6-18 GHz. IEEE Transactions on Geosciences and Remote Sensing, 37, 79-93. http://dx.doi.org/10.1109/36.739125

[24] Njoku, E.G., Jackson, T.J., Lakshmi, V., Chan, T.K. and Nghiem, S.V. (2003) Soil Moisture Retrieval from AMSR-E. IEEE Transactions on Geosciences and Remote Sensing, 41, 215-229.

[25] Paloscia, S., Macelloni, G. and Santi, E. (2006) Soil Moisture Estimates from AMSR-E Brightness Temperatures by Using a Dual-Frequency Algorithm. IEEE Transactions on Geosciences and Remote Sensing, 44, 3135-3144. http://dx.doi.org/10.1109/TGRS.2006.881714

[26] Li, L., Njoku, E.G., Im, E., Chang, P.S. and Germain, K.S. (2004) A Preliminary Survey of Radio-Frequency Interference over the U.S. in Aqua AMSR-E Data. IEEE Transactions on Geosciences and Remote Sensing, 42, 380-390. http://dx.doi.org/10.1109/TGRS.2003.817195

[27] Njoku, E.G., Ashcroft, P., Chan, T.K. and Li, L. (2005) Global Survey and Statistics of Radio-Frequency Interference in AMSR-E Land Observations. IEEE Transactions on Geosciences and Remote Sensing, 43, 938-947. http://dx.doi.org/10.1109/TGRS.2004.837507

[28] Ellingson, S.W. and Johnson, T.J. (2006) A Polarimetric Survey of Radio-Frequency Interference in C- and X-Bands in the Continental United States Using WindSat Radiometry. IEEE Transactions on Geosciences and Remote Sensing, 44, 540-548. http://dx.doi.org/10.1109/TGRS.2005.856131 
[29] Kidd, C. (2006) Radio Frequency Interference at Passive Microwave Earth Observation Frequencies. International Journal of Remote Sensing, 27, 3853-3865. http://dx.doi.org/10.1080/01431160600702400

[30] Fujii, H., Koike, T. and Imaoka, K. (2009) Improvement of AMSR-E Algorithm for Soil Moisture Estimation by Introducing a Fractional Vegetation Coverage Dataset Derived from MODIS Data. Journal Remote Sensing Society Japan, 29, 282-292.

[31] Koike, T., Nakamura, Y., Kaihotsu, I., Davva, G., Matsuura, N., Tamagawa, K. and Fujii, H. (2004) Development of an Advanced Microwave Scanning Radiometer (AMSR-E) Algorithm of Soil Moisture and Vegetation Water Content. Annual Journal Hydraulic Engineering, Japan Society Civil Engineering, 48, 217-222.

[32] Fujii, H., Koike, T., Ohta, T., Ishidaira, H., Jackson, T. and Heathman, G. (2000) Soil Moisture Observation under Different Vegetation Conditions by GBMR. Proceedings of 2000 IEEE Geosciences and Remote Sensing Society Meeting, 1268-1270.

[33] Njoku, E. and Chan, S. (2006) Vegetation and Surface Roughness Effects on AMSR-E Land Observations. Remote Sensing Environment, 100, 190-199. http://dx.doi.org/10.1016/j.rse.2005.10.017

[34] Osterkamp, T.E. (2003) Establishing Long-Term Permafrost Observatories for Active-Layer and Permafrost Investigations in Alaska: 1977-2002. Permafrost and Periglacial Processes, 14, 331-342. http://dx.doi.org/10.1002/ppp.464

[35] Osterkamp, T.E. and Romanovsky, V.E. (1999) Evidence for Warming and Thawing of Discontinuous Permafrost in Alaska. Permafrost and Periglacial Processes, 10, 17-37. http://dx.doi.org/10.1002/(SICI)1099-1530(199901/03)10:1<17::AID-PPP303>3.0.CO;2-4

[36] Romanovsky, V.E. and Osterkamp, T.E. (1995) Inter-Annual Variations of the Thermal Regime of the Active Layer and Near-Surface Permafrost in Northern Alaska. Permafrost and Periglacial Processes, 6, 313-335. http://dx.doi.org/10.1002/ppp.3430060404

[37] Romanovsky, V.E. and Osterkamp, T.E. (1997) Thawing of the Active Layer on the Coastal Plain of the Alaskan Arctic. Permafrost and Periglacial Processes, 8, 1-22. http://dx.doi.org/10.1002/(SICI)1099-1530(199701)8:1<1::AID-PPP243>3.0.CO;2-U

[38] Muskett, R.R. (2012) Remote Sensing, Model-Derived and Ground Measurements of Snow Water Equivalent and Snow Density in Alaska. International Journal of Geosciences, 3, 1127-1136. http://dx.doi.org/10.4236/ijg.2012.35114

[39] Romanovsky, V.E., Smith, S.L. and Christiansen, H.H. (2010) Permafrost Thermal State in the Polar Northern Hemisphere during the International Polar Year 2007-2009: A Synthesis. Permafrost and Periglacial Processes, 21, 106-116. http://dx.doi.org/10.1002/ppp.689

[40] Romanovsky, V.E., Drozdov, D.S., Oberman, N.G., Malkova, G.V., Kholodov, A.L., Marchenko, S.S., Moskalenko, N.G., Sergeev, D.O., Ukraintseva, N.G., Abramov, A.A., Gilichinsky, D.A. and Vasiliev, A.A. (2010) Thermal State of Permafrost in Russia. Permafrost and Periglacial Processes, 21, 136-155. http://dx.doi.org/10.1002/ppp.683

[41] Smith, S.L., Romanovsky, V.E., Lewkowicz, A.G., Burn, C.R., Allard, M., Clow, G.D., Yoshikawa, K. and Throop, J. (2010) Thermal State of Permafrost in North America: A Contribution to the International Polar Year. Permafrost and Periglacial Processes, 21, 117-135. http://dx.doi.org/10.1002/ppp.690

[42] Christiansen, H.H., Etzelmüller, B., Isaksen, K., Juliussen, H., Farbrot, H., Humlum, O., Johansson, M., Ingeman-Nielsen, T., Kristensen, L., Hjort, J., Holmlund, P., Sannel, A.B.K., Sigsgaard, C., Åkerman, H.J., Foged, N., Blikra, L.H., Pernosky, M.A. and Ødegård, R.S. (2010) The Thermal State of Permafrost in the Nordic Area during the International Polar Year 2007-2009. Permafrost and Periglacial Processes, 21, 156-181. http://dx.doi.org/10.1002/ppp.687

[43] Zhao, L., Wu, Q., Marchenko, S.S. and Sharkhuu, N. (2010) Thermal State of Permafrost and Active Layer in Central Asia during the International Polar Year. Permafrost and Periglacial Processes, 21, 198-207. http://dx.doi.org/10.1002/ppp.688

[44] Seyfried, M.S. and Murdock, M.D. (2004) Measurement of Soil Water Content with a 50-MHz Soil Dielectric Sensor. Soil Science Society of America Journal, 68, 394-403. http://dx.doi.org/10.2136/sssaj2004.3940

[45] Seyfried, M.S., Grant, L.E., Du, E. and Humes, K. (2005) Dielectric Loss and Calibration of the Hydra Probe Soil Water Sensor. Vadose Zone Journal, 4, 1070-1079. http://dx.doi.org/10.2136/vzj2004.0148

[46] Topp, G.C., Davis, J.L. and Annan, A.P. (1980) Electromagnetic Determination of Soil Water Content: Measurement in Coaxial Transmission Lines. Water Resources Research, 16, 574-582. http://dx.doi.org/10.1029/WR016i003p00574

[47] Roth, K., Schulin, R., Flühler, H. and Attinger, W. (1990) Calibration of Time Domain Reflectometry for Water Content Measurement Using a Composite Dielectric Approach. Water Resources Research, 26, 2267-2273.

[48] Zimov, S.A. (2005) Pleistocene Park: Return of the Mammoth’s Ecosystem. Science, 308, 796-798. http://dx.doi.org/10.1126/science.1113442

[49] Beget, J.E., Hopkins, D.M. and Charron, S.D. (1996) The Largest Known Maars on Earth, Seward Peninsula, North- 
west Alaska. Arctic, 49, 62-69. http://dx.doi.org/10.14430/arctic1184

[50] Seiradakis, J.H., Reich, W., Wielebinski, R., Lansenby, A.N. and Yusef-Zadeh, F. (1989) Radio Continuum Observations of the Galactic Centre at 4.75 and 10.7 GHz. Astronomy and Astrophysics, 81, 291-302.

[51] Bianchi, C. and Meloni, A. (2007) Natural and Man-Made Terrestrial Electromagnetic Noise: An Outlook. Annals of Geophysics, 50, 435-445. 
Scientific Research Publishing (SCIRP) is one of the largest Open Access journal publishers. It is currently publishing more than 200 open access, online, peer-reviewed journals covering a wide range of academic disciplines. SCIRP serves the worldwide academic communities and contributes to the progress and application of science with its publication.

Other selected journals from SCIRP are listed as below. Submit your manuscript to us via either submit@scirp.org or Online Submission Portal.
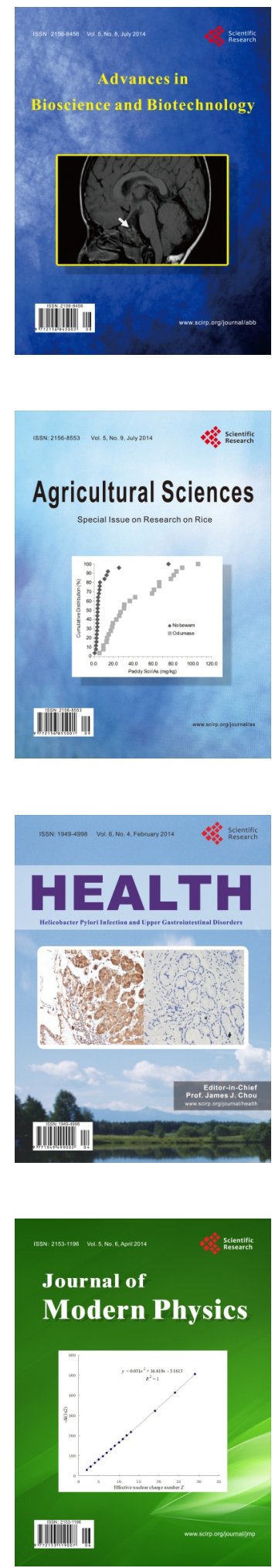
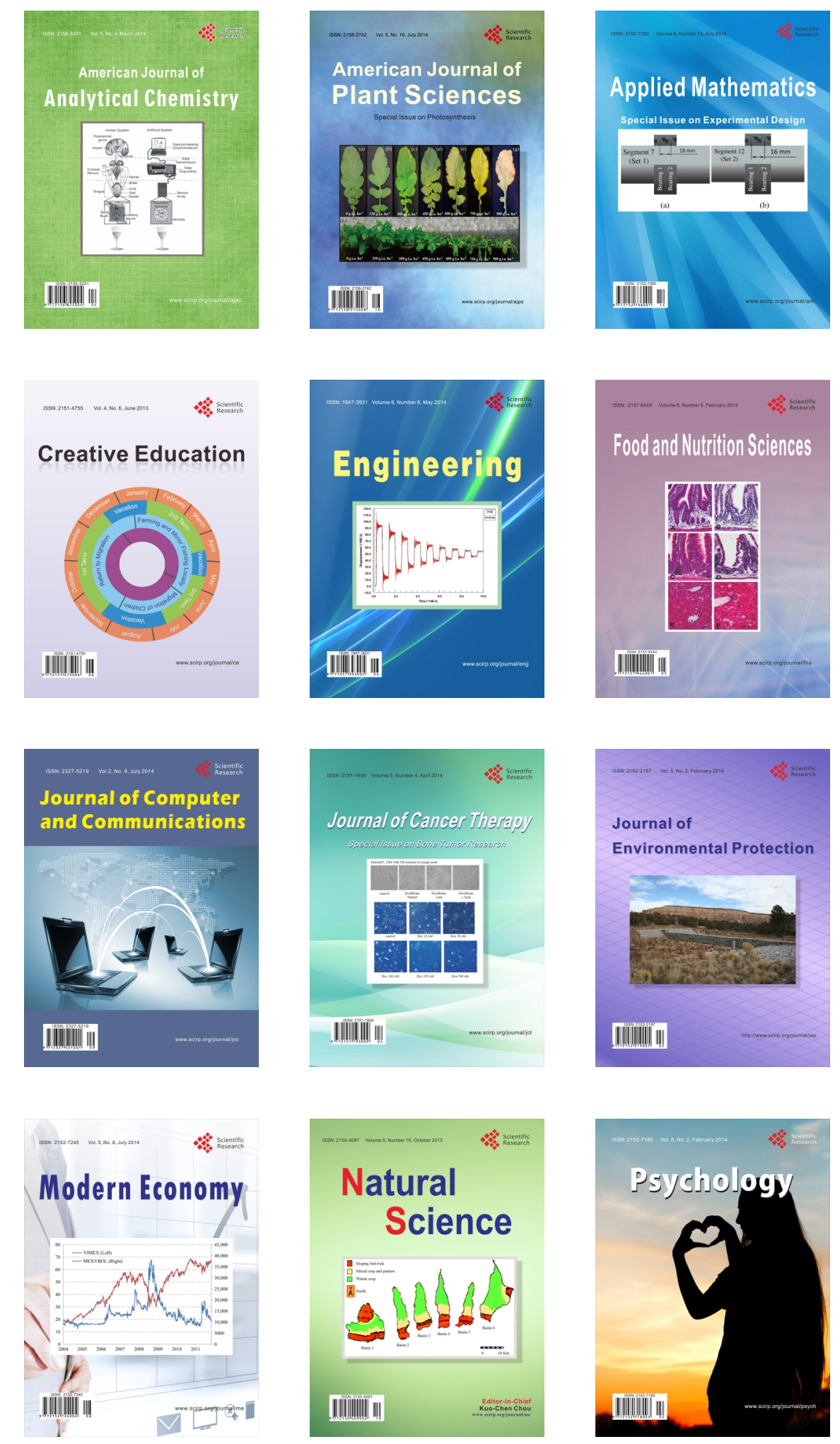